\title{
Supersonic/Hypersonic Correlations for In-Cavity Transition and Heating Augmentation
}

\author{
Joel L. Everhart* \\ NASA Langley Research Center, Hampton, VA, 23681
}

Laminar-entry cavity heating data with a non-laminar boundary layer exit flow have been retrieved from the database developed at Mach 6 and 10 in air on large flat plate models for the Space Shuttle Return-To-Flight Program. Building on previously published fully laminar and fully turbulent analysis methods, new descriptive correlations of the in-cavity floor-averaged heating and endwall maximum heating have been developed for transitional-to-turbulent exit flow. These new local-cavity correlations provide the expected flow and geometry conditions for transition onset; they provide the incremental heating augmentation induced by transitional flow; and, they provide the transitional-to-turbulent exit cavity length. Furthermore, they provide an upper application limit for the previously developed fully-laminar heating correlations. An example is provided that demonstrates simplicity of application. Heating augmentation factors of 12 and 3 above the fully laminar values are shown to exist on the cavity floor and endwall, respectively, if the flow exits in fully tripped-to-turbulent boundary layer state.

Cavity floor heating data in geometries installed on the windward surface of 0.075 -scale Shuttle wind tunnel models have also been retrieved from the boundary layer transition database developed for the Return-To-Flight Program. These data were independently acquired at Mach 6 and Mach 10 in air, and at Mach 6 in $\mathrm{CF}_{4}$. The correlation parameters for the floor-averaged heating have been developed and they offer an exceptionally positive comparison to previously developed laminar-cavity heating correlations. Non-laminar increments have been extracted from the Shuttle data and they fall on the newly developed transitional in-cavity correlations, and they are bounded by the $95 \%$ correlation prediction limits. Because the ratio of specific heats changes along the re-entry trajectory, turning angle into a cavity and boundary layer flow properties may be affected, raising concerns regarding the application validity of the heating augmentation predictions. Significantly, these experiments and analysis showed no local cavity-heatingaugmentation differences between tests conducted in air $(\gamma=1.4)$ and $\mathrm{CF}_{4}(\gamma=1.1)$.

\begin{tabular}{ll}
$\mathrm{a}, \mathrm{b}$ & \multicolumn{1}{c}{ Nomenclature } \\
$\mathrm{BF}$ & correlation curve fit coefficients \\
$\mathrm{BF}_{\mathrm{AVG}}$ & average Bump Factor on the cavity floor \\
$\mathrm{BF}_{\mathrm{MAX}}$ & maximum Bump Factor immediately downstream of the cavity end wall \\
$\mathrm{C}_{\mathrm{p}}$ & pressure coefficient \\
$\mathrm{h}$ & heat transfer coefficient, $\mathrm{h}=\mathrm{q} /\left(\mathrm{H}_{\mathrm{aw}}-\mathrm{H}_{\mathrm{w}}\right),\left(\mathrm{lbm} / \mathrm{ft}^{2} / \mathrm{s}\right)$ \\
$\mathrm{L}, \mathrm{W}, \mathrm{H}$ & cavity length, width, and depth $(\mathrm{in})$ \\
$\mathrm{LCL} / \mathrm{UCL}$ & lower/upper confidence limit \\
$\mathrm{LPL} / \mathrm{UPL}$ & lower/upper prediction limit \\
$\mathrm{M}$ & Mach number \\
$\mathrm{M}_{\mathrm{e}}$ & boundary layer edge Mach number at the cavity entrance
\end{tabular}

* Senior Research Engineer, Aerothermodynamics Branch, and AIAA Associate Fellow. 


$\begin{array}{ll}\mathrm{R}^{2} & \text { Linear Correlation Coefficient } \\ \mathrm{Re} & \text { unit Reynolds number }(1 / \mathrm{ft}) \\ \mathrm{Re}_{\theta} & \text { momentum thickness Reynolds number } \\ \mathrm{X} & \text { axial distance from model leading edge (in) } \\ \mathrm{X}_{\mathrm{MAX}} & \text { location where BF } \\ \mathrm{y} & \text { spanwise distance from model centerline (in) } \\ \mathrm{z} & \text { distance normal to x-y plane (in) } \\ \alpha & \text { angle-of-attack (deg) } \\ \alpha, \beta, \sigma, \tau & \text { Bump Factor correlation powers } \\ \gamma & \text { ratio of specific heats } \\ \delta & \text { boundary layer thickness (in) } \\ \theta & \text { boundary layer momentum thickness (in) }\end{array}$

Subscripts

$\begin{array}{ll}\text { AVG } & \text { average value in cavity } \\ \text { Lam } & \text { laminar } \\ \text { MAX } & \text { maximum value on cavity centerline immediately downstream of endwall } \\ \text { Turb } & \text { turbulent } \\ \text { tr } & \text { transitional } \\ \infty & \text { freestream static conditions }\end{array}$

\section{Introduction}

Following the February 1, 2003 loss of the Space Shuttle Columbia during flight STS-107, the Columbia Accident Investigation Board (CAIB) recommended that NASA "Develop, validate, and maintain physics-based computer models to evaluate thermal protection system (TPS) damage from debris impacts" for application to future flights. ${ }^{1}$ An extensive literature search ${ }^{2}$ revealed that much general information was available on cavity flow physics and heating; however, specific information required to address issues associated with random damage to the Orbiter was very sparse. The existing data were acquired using the discrete measurement methods available prior to the global surface techniques now available. Neither the archival experiments nor the available theories adequately captured the three-dimensional cavity physics because they missed the vortex development on the cavity top sidewall corners, on the floor of the cavity, and downstream of the cavity on the outside edges. Most of the published information was for turbulent flow conditions and little information was available across the wide spectrum of possible geometry variations or range of local flow conditions. This sparseness also presented modeling challenges for the computational community since appropriate validation data were unavailable. Because of this, experimental screening tests begun at Langley Research Center during the CAIB investigations ${ }^{3}$ were continued through the Shuttle Return-To-Flight Program (RTF). ${ }^{2,4,5,6}$ The resulting predominately-laminar experiments created a cavity-heating database consisting of nearly 800 wind tunnel runs that formed the foundation of the Cavity Heating Tool as discussed by Anderson, et al. ${ }^{7}$ These data also included a basic set of tripped-turbulent cavityentry conditions to establish heating levels that would occur if non-laminar exit conditions were realized. Even though the desired laminar entry conditions could be specified, the cavity exit conditions could not be ensured because of the flow disturbance offered by the cavity. As a result, transitional boundary layer heating data both within and downstream of the cavity were 
acquired as a byproduct of the testing. After excluding the non-laminar exit data, continued analysis of the fully laminar data allowed development of heating correlations for the floor averaged heating and the endwall heating augmentation. These are reported in Reference 8. Subsequently, these correlations were modified for fully turbulent data, and these are reported in Reference 9.

The first purpose of this paper is to analyze the non-laminar-exit cavity data to provide a prediction of in-cavity boundary layer transition and to define the resulting heating augmentation. Successful correlation of the transition process will provide an upper application limit for the laminar heating predictions. Though acquired during the original testing, all data used in this analysis were excluded during screening for development of the laminar and turbulent correlations; thus, this presentation represents a first use application. All of the developmental data were acquired over a period of years on large flat plate models in multiple tests in air at Mach 6 and Mach 10.

Boundary layer transition occurring downstream of a cavity on Space Shuttle Orbiter models was also investigated by Horvath, et al. for the RTF. ${ }^{10}$ The wind tunnel experiments were performed at Mach 6 and 10 in air and at Mach 6 in $\mathrm{CF}_{4}{ }^{11}$ The Orbiter model-scale cavities were typically very small; however, imaging of the larger cavities provided data of sufficient resolution and quality for use as an independently acquired validation data set. The second purpose of this paper is to offer an independent consistency confirmation of the previously developed laminar heating correlations. Next, the Shuttle cavity data are used to independently verify and assess the cross-model applicability of the newly developed in-cavity transition relationships. And since the ratio of specific heats changes along the trajectory during re-entry, a final purpose is to assess the impact of this change on cavity heating, thereby reducing uncertainty in the damage assessment process.

\section{Supersonic/Hypersonic Cavity Flow Physics}

The literature survey presented in Ref. 2 provides the following overview of cavity flow physics, as provided by an approximately Mach 3 turbulent incoming boundary layer. Typically, length-to-depth ratio $(\mathrm{L} / \mathrm{H})$ is used to distinguish between and classify different cavity flow regimes $^{12,13}$, as depicted in Figure 1 . The impact of cavity depth ratio, $H / \delta$, is typically assessed via the use of "thin" and "thick" boundary layers.

Very short or deep cavities with $\mathrm{L} / \mathrm{H}<1$ are known as gaps. In this case, the mainstream flows over the gap and its shearing causes the formation of a column of counter-rotating vortices within the gap, numbering approximately H/L. Alternating hot spots are developed on the sidewalls when the vortices directionally align.

Two stable-structure flow environments exist for cavities with length $\mathrm{L} / \mathrm{H}>1$. The first is a short cavity in the length range $1 \leq \mathrm{L} / \mathrm{H} \leq 10$, defined as an open cavity. The mainstream flow does not enter the cavity directly, though there may be some mass interchange with the lowenergy vortical flow inside the cavity. Physically, the flow skims over a short cavity because it has insufficient length to support the required entry and exit turning angles. The pressure in the cavity is typically above the ambient and climbs to a peak at the downstream lip. The heating drops to values significantly below the undisturbed value and rises slowly to a peak value on the downstream lip.

The other stable-structure environment is a long cavity, also known as a closed cavity, with length $\mathrm{L} / \mathrm{H} \geq 14$. In this case, three distinct sub-flows will develop if the cavity is long enough. First, the upstream flow is now able to turn into the cavity and impinge on the floor, creating an 
aft-facing-step flow field. Next, a boundary layer on the floor may develop and recover to the ambient level outside the cavity. Finally, as the flow approaches the endwall it will turn outward and create a three-dimensional forward-facing-step flow field. For long, deep cavities, the pressure gradients may be severe where the flow turns and strong expansion and shock waves will be generated. Viscous shearing generated by this flow turning will augment the heating to levels significantly higher than the ambient levels on both the cavity floor and the endwall. The pressure in these long cavities will decrease below the ambient and steadily increase downstream, reaching large values of over-pressure behind the shocks. Vortices will develop on the cavity sidewalls as the flow expands around the corner into the cavity and on the floor after flow impingement, further augmenting the heating, which may extend laterally around the cavity in the most severe cases. These vortices will interact with the cavity endwall and spill into the downstream region. Given laminar inflow, analysis of the heating profiles indicates that most any type of outflow may occur, depending on the cavity and its environment. The in-cavity boundary layer flow may remain laminar, become transitional, or it can exist in a fully turbulent state; the downstream possibilities are equally varied. ${ }^{14}$

Transitional cavities occurring in the range $10 \leq \mathrm{L} / \mathrm{H} \leq 14$ represent an unstable flow state where the flow alternates between the two bounding stable-state flow environments. Oil flow visualizations of both open and closed conditions occurring in the same cavity model have been presented by Stallings, et al. ${ }^{15}$ Transitional cavities were avoided when possible in the present tests because of the instrumentation complexity and the additional data analysis challenges.

The boundaries between the different cavity flow regimes are nominal, at best. For example, different researchers have measured $\mathrm{L} / \mathrm{H}$ values ranging from 9 to 11 as the upper limit for open cavities and from 12 to 15 as the lower limit for closed cavity flow. These limits should therefore be taken only as a guide. An open question posed in Ref. 2 regarding the effect of $\gamma$ on the cavity in-flow turning angle on the flow regime boundary definitions will be addressed in this report.

\section{Data Sources}

Cavity data used in the developmental analysis were acquired during 5 different wind tunnel experiments that were conducted over a period of 3 years in the NASA Langley Aerothermodynamics Laboratory (LAL), including the 20-Inch Mach 6 Air and 31-Inch Mach 10 Air Tunnels. ${ }^{11}$ Global heating was measured using the two-color phosphor thermography method $^{16}$. Only steady-state measurements were acquired and all conclusions were inferred from the phosphor measurements. Since the flat plate cavity tests were conducted sequentially, each test generally had a different objective, building on and incorporating knowledge gained from preceding experiments. Thus, differences exist in how each was conducted, adding increased credibility to the derived uncertainty estimates. Figure 2 shows a simple sketch of the coordinate system used for the flat plate cavity models. The rational for selecting the base plate geometry parameters is discussed in each of the supporting test report documents. A brief overview of the cavity heating tests conducted on flat plates follows.

Cavity Heating Test 6868 (T6868) conducted in the 20-Inch Mach 6 Air Tunnel. ${ }^{3}$ This test encompassing 156 runs was a preliminary screening experiment designed to investigate the aeroheating characteristics of long cavities $(\mathrm{L} / \mathrm{H} \geq 14)$. Results of this study provided fundamental information that enabled the rational design of subsequent experiments.

Cavity Heating Test 6888 (T6888) conducted in the 20-Inch Mach 6 Air Tunnel. ${ }^{2}$ This test was the primary database experiment used to develop the Cavity Heating Tool $^{7}$ in support of the Shuttle Return-To-Flight Program. This 357 run experiment included a large range of non- 
dimensional baseline (rectangular geometry) cavity parameters, including length $(\mathrm{L} / \mathrm{H})$, width $(\mathrm{W} / \mathrm{H})$, and depth $(\mathrm{H} / \delta)$. Also in these data were wide ranging geometry excursions designed to examine the heating effects due to randomness in the damage geometry, including symmetrical planform, profile, and cross-section variations. The impact of asymmetrical geometry variations included skewed cavities whose major axis was misaligned with the main flow and cavities with longitudinal depth variations. Laminar and turbulent boundary layer edge flow conditions entering the cavity were acquired over a wide range of flow conditions. The data were acquired on a flat, near-zero-gradient pressure surface using cast ceramic cavity geometries. Post-test analysis of these data revealed that significant reductions in data uncertainty could be achieved by future testing in the higher temperature Mach 10 facility.

Cavity Heating Test 404 (T404) conducted in the 31-Inch Mach 10 Air Tunnel. ${ }^{5}$ The emphasis of this 49 run test was shallower, smaller cavities than were achievable during T6888. It was conducted as a rapid-response investigation immediately prior to and during the launch of STS114 to address potential deficiencies in the existing cavity heating database. All geometries were rectangular, baseline configurations that were laser-ablated into a flat, ceramic, near-zerogradient pressure surface.

Cavity Heating Test 406 (T406) conducted in the 31-Inch Mach 10 Tunnel. ${ }^{4}$ This test was designed to evaluate the impact of a known, controlled pressure gradient on the local heating of the baseline rectangular geometry. Two test-surface contours were provided, including an expansion-gradient surface and a zero-gradient surface for comparison. Single short and long cavities were machined into the ceramic model on its centerline, providing sharp, high-quality cavity configurations. The 75 data runs were designed to provide CFD code calibration quality information.

Cavity Heating Test 423 (T423) conducted in the 31-Inch Mach 10 Tunnel. ${ }^{6}$ This test was designed to provide a direct comparison between a real, impact-induced geometry and the corresponding idealized geometry used for tool development and damage assessment. Cavities used in this 48-run experiment were cast into the ceramic model because of the ragged, nonuniform surfaces prevalent in the impact cavities. Data were also acquired on a flat, zero-gradient pressure surface; only the idealized geometries are used in this analysis.

Shuttle Cavity Tests. Horvath, et al, investigated boundary layer transition induced by cavity damage to the Shuttle Orbiter windward surface in the LAL. ${ }^{10}$ Test 6887 (T6887) was conducted in the 20-Inch Mach 6 Air Tunnel; Test 159 (T159) was conducted in the 20-Inch Mach $6 \mathrm{CF}_{4}$ Tunnel; and, Test 352 (T352) was conducted in the 31-Inch Mach 10 Air Tunnel. ${ }^{11}$ The three test entries encompassed a total of 583 wind tunnel runs. Global heating was measured using the two-color phosphor thermography method ${ }^{17}$. Since a different researcher, with different test objectives, using different wind tunnel models, independently conducted these tests they offer a credible source of cavity heating validation data. The basic coordinate system for the Shuttle cavities is the same as that provided in Figure 2.

\section{Experimental Methods}

This section presents a brief discussion of the experimental methods. The test facility is first discussed, followed by a description of the models and cavity design, and an overview of the phosphor thermography data system used to acquire the global heating measurements. Finally, the data reduction and presentation parameters are described. 


\section{A. Facilities}

Three conventional blowdown wind tunnel facilities in the Aerothermodynamics Laboratory at the NASA Langley Research Center were used to develop the cavity-heating database. Large flat plate cavity models and 0.075-percent Shuttle were tested in the 20-Inch Mach 6 Air Tunnel and the 31-Inch Mach 10 Air Tunnel, where $\gamma=1.4$. The Shuttle models were also tested in the 15-Inch Mach $6 \mathrm{CF}_{4}$ Tunnel, where $\gamma=1.1$. Respectfully, the nominal unit Reynolds number ranges for these facilities are $0.5-7.4 \times 10^{6} / \mathrm{ft}, 0.25-2.2 \times 10^{6} / \mathrm{ft}$, and $0.04-0.73 \times 10^{6} / \mathrm{ft}$. These facilities are described in detail in Micol. ${ }^{11}$ Flow properties for each facility were determined using the GASPROPS code developed by Hollis. ${ }^{18}$ No attempt was made to evaluate highenthalpy or tunnel-noise effects.

\section{B. Models}

A schematic showing the flat plate model coordinate system orientation that was used for design and installation is presented Figure 2. The x-axis is measured down the length of the model from the virtual origin located at the intersection of the nose wedge, and the z-axis is measured normal to the surface. For data analysis, the origin is transferred to the cavity entrance in a later-discussed scaled coordinate system. Cavity insert models developed to support T6868 and T6888 utilized a strut-mounted 10 -inch-wide by 28 -inch-long steel flat-plate model having a blunted leading edge with a radius of 0.125 inches. Cavities were typically installed upstream at the 8-inch station with boundary layer entrance conditions being defined using model angle of attack and tunnel conditions. However, several cavity models were designed with downstream locations to maximize the achievable $\operatorname{Re}_{\theta}$ and $\delta$. Details are provided in the test reports. Figure 3 presents a 20-Inch Mach 6 Air Tunnel model installation photograph. The blunt nose model provides edge Mach numbers of approximately 2.9 to 3 at zero incidence (see Ref. 2) as required to match Orbiter flight surface conditions. ${ }^{3}$ The integrity of the blunted nose geometry is easier to maintain compared to a sharp nose configuration. The model includes an upstream insert region where boundary layer trips can be installed, as shown in the figure. Boundary layer trip hardware and tripping methods developed by Berry, et al. ${ }^{19,20}$ were used to ensure turbulent flow over the model. Based on the results presented in Ref. 20, the height of the trip, k, was determined from $\mathrm{k} / \delta=0.6$ for the present flow conditions. Off-design test conditions were examined to ensure fully tripped turbulent boundary layer conditions. Turbulent flow boundary layer edge properties were computationally obtained by matching solutions with experimentally obtained heating measurements on the plate surface. ${ }^{9}$ A discussion of the boundary layer trips and the baseline heating data are presented in Ref. 2. The model also includes a 4-inch wide by 18-inch long test region starting 7.5 inches from the virtual origin for test articles. A representative example of the cavity inserts is shown in Figure 4. Ceramic insert models used for these tests experienced step/gap sealing issues that were resolved using 0.003-inch thick Kapton tape. Models manufactured for T404, T406, and T423 eliminated step-gap sealing issues by casting the entire test plate surface as a single 10 -inch-wide by 20 -inch-long ceramic piece (see Figure 5). A 0.125-inch radius nose was also used with these models. All models were fabricated using ceramic casting methods as described in Buck, et al. ${ }^{21,22}$ After fabrication, the models were coated with a nominal $27 \mu \mathrm{m}$ thick mixture of phosphors suspended in a silica-based colloidal binder $^{23}$ and sent to quality assurance for measurement and application of small circular locating markers, known as fiducial marks.

Standard ceramic casting methods were used to fabricate the 14 sting-mounted 0.075 -scale Shuttle models used during the cavity-induced boundary layer transition experiments ${ }^{10}$. Each of 
the cavities was laser ablated into the surface on the model windward centerline beginning at station $\mathrm{x} / \mathrm{L}=0.3$. Figure 6 presents a photograph taken from reference 10 showing the model being ablated to manufacture a typical large cavity shown in Figure 7. Surface roughness of the uncoated models was approximately 200 micro-inches (rms) and approximately 400 microinches on the phosphor-coated models. The reader is referred to Ref. 10 for further details.

\section{Cavity Designs and Test Conditions}

The range of cavity entrance flow conditions and the geometry parameters tested during the flat plate and the Shuttle model experiments are listed in Table 1. Experiments conducted on the flat plate were designed to capture local cavity heating effects. Experiments conducted on the Shuttle Orbiter models were designed to capture downstream effects due to cavity-induced boundary layer transition.

The flat plate model cavities were geometrically and fluid-dynamically scaled for the damage assessment modeling requirements of the Shuttle Orbiter. Accordingly, a maximum cavity depth constraint was established based on the nominal three-inch thickness of the thermal protection system tiles; damage greater than this depth constitutes a breach of the aluminum substructure. Because of the launch configuration, impact damage on the forward portion of the vehicle is likely to be deep and short, in contrast to long, shallow grazing damage that is likely on the aft portion of the vehicle. Parametric variations used to establish the cavity-heating database were guided by these considerations.

Typical surface flow conditions for the windward surface of the Shuttle Orbiter were obtained from Campbell, et al. ${ }^{24}$ to establish the parameter variations at the cavity entrance, $\left(\mathrm{M}_{\mathrm{e}}, \mathrm{Re}_{\theta}\right.$, $\delta)_{\text {Flight }}$ Viscous solutions of the centerline test article surface conditions were determined for both the Mach 6 and Mach 10 Air Tunnel freestream conditions from two-dimensional centerline contour simulations of the baseline geometry using the LAURA code ${ }^{25,26}$. The range of the computationally determined $\left(\mathrm{M}_{\mathrm{e}}, \mathrm{Re}_{\theta}\right)_{\text {Tunnel }}$ conditions were matched to flight. The boundary layer thickness ratio $\left(\delta_{\text {Tunnel }} / \delta_{\text {Flight }}\right)$ was used to scale flight damage scenarios to tunnel scale.

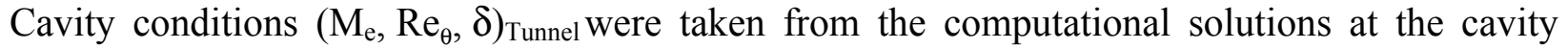
entrance. Cavity entrance was at $\mathrm{x}=8$ inches to place the cavity in a region of nearly constant, almost zero pressure gradient. This forward placement of the cavity helps minimize the effects of spanwise gradients, which increase for aft locations on the flat plate model as the side-edge vortices develop toward the plate centerline. Further details of the scaling process may be found in Everhart, et al. ${ }^{2}$

The cavity geometries considered here have flat bottoms and rectangular planforms and cross sections. Both open and closed cavities were considered. These baseline geometries were easy to define and they were the primary geometry used by Anderson, et al. to develop the Cavity Heating Tool ${ }^{7}$. This simple geometry could be distinguished according to a number of nondimensional parameters, including $\mathrm{H} / \delta, \mathrm{W} / \mathrm{H}$, and $\mathrm{L} / \mathrm{H}$. Though the database includes nonrectangular cavities designed to examine the random effects due to an impact, they are not included in this analysis. Specifics of the cavities and their designs are included in the previously cited database publications by Everhart, et al.

Cavities tested on the Shuttle models were rectangular baseline geometries with flat bottoms, as described above for the flat plates and shown in Figure 7. These cavities were installed on the windward surface model centerline with the leading edge at station $\mathrm{x} / \mathrm{L}=0.3$. Cavity dimensions are presented in 
Table 2. Because the longest cavity was about 0.6 inch and because the camera was imaging the entire model, few pixels were available for analysis in the smallest of the cavities (C1-C3). Therefore, accurate heating measurements for the shortest cavities were difficult to obtain due to inadequate pixel resolution.

\section{Phosphor Thermography Technique}

Global surface heating distributions were calculated using the two-color, relative-intensity, phosphor thermography aeroheating measurement method and associated codes ${ }^{16}$. This is the standard method for obtaining aeroheating data in NASA Langley's hypersonic wind tunnels, and it can be used to identify the surface heating effects of complex three-dimensional flow phenomena, which are difficult to examine using conventional discrete-sensor methods. With this method, ceramic wind tunnel models are coated with phosphor crystals that fluoresce in the red and green regions of the visible light spectrum when illuminated by ultraviolet (UV) light. The phosphor-coated model is exposed to the heated flow during a wind tunnel run, and the resulting changes in fluorescence intensity of the model are recorded and digitized. The surface temperature distributions are determined from the fluorescence intensities through prior calibrations and analyzed using the IHEAT code, and they may be mapped onto a 3-dimensional CAD representation of the test article using the MAP3D code. Phosphor thermography on a hemisphere has been shown to agree with thin-film measurements and CFD to within $\pm 7.5 \%$ near the stagnation point and to within $\pm 15 \%$ on the backend ${ }^{16}$.

A cavity heating uncertainty analysis was performed for experiments conducted in the 20Inch Mach 6 Tunnel. Representative within-run total and bias uncertainties for open cavity flows are typically less than $10 \%$ over the flat plate surface. In the cavity where the lowest temperatures are experienced, the bias uncertainties are about $10 \%$, while the total uncertainties approach $20 \%$. For the closed conditions where the flow enters the cavity, the temperature rise is generally greater, resulting in lower with-in run bias uncertainties (3-4 percent or lower) with the exception of the low temperature regions on the cavity floor. Total within-run uncertainties are in the 10-20 percent range. An assessment of the with-in test uncertainties, including run-to-run, model-to-model, etc. can be found in the "The Cavity Heating Tool" documentation. ${ }^{7}$ Heating experiments conducted in the 31-Inch Mach 10 Tunnel experience significantly larger surface temperatures, resulting in a larger thermal driving potential. Run temperatures in the cavity region are typically $20^{\circ}-40^{\circ} \mathrm{F}$ larger that pre-run temperatures, yielding a much higher signal-tonoise ratio. As a result, uncertainties for the Mach 10 experiments are much lower than those in experienced at Mach 6.

\section{E. Data Reduction}

The impact of the scaled cavity on the local undisturbed environment was assessed by converting the local heating data to heating augmentation or bump factor (BF) format by normalizing the measured $h_{\text {local }}$ by an averaged reference-location heating $h_{A V G}$, yielding $B F=h_{\text {local }} / h_{A V G}$. For analysis consistency, $h_{A V G}$ is computed ahead of each cavity over the length $-3 \leq x / H \leq-1$. This averaging-region definition ensured that a consistent reference location was used when the data were converted to scaled-cavity space. Additionally, shearing is increased as the flow turns into the cavity, inducing a heating peak upstream of the cavity leading edge. This location avoids a heating bias when averaging over the reference area. In this format, $B F=1$ becomes the nominal, undisturbed condition for a flat plate. Two metrics, $B F_{A V G}$ and $B F_{M A X}$, are used to characterize the cavity heating. $B F_{A V G}$ was determined by averaging all imaged data inside the entire large cavities used for T6888. Only a small number of non-floor 
pixels were present because the camera imaging was such that the upstream endwall was not visible and only 2-3 pixels were visible in any longitudinal linecut on the downstream cavity endwall. Likewise, only one of the sidewalls was imaged and, typically, only 1-2 pixels were visible in any spanwise linecut. This area averaging greatly reduced noise in the data caused by the low temperatures experienced on the cavity floor for T6888. $B F_{A V G}$ was determined using only the centerline distribution on the cavity floor between $0.15 \leq x / L \leq 0.85$ for T404, T406, and T423. Both methods were used in Reference 2 and differences were within data scatter. $B F_{M A X}$ was determined as the maximum value downstream of the cavity endwall. For T6888, offcenterline maximum values were considered; however, only centerline values were considered for T404, T406, and T423.

\section{Representative Test Data and Parameter Space}

Representative data taken from T6888 in bump factor format are presented here to provide an overview of the cavity-heating database and to demonstrate the flow physics considered for screening fully laminar cavity conditions. While laminar-entry flow can be prescribed, laminarexit flow from the cavity cannot be ensured - the cavity disturbance may act as a trip. For the initial laminar correlation analysis ${ }^{8}$, all of the data were closely screened to ensure the existence of laminar-exit conditions using both laminar and tripped-turbulent measurements made on baseline, no-cavity models to establish the respective entry/exit heating levels (see Ref. 2). Transitional flow exiting a cavity will increase and approach the turbulent level in the downstream farfield. Both transitional and fully developed turbulent heating levels were observed within the cavities for select laminar-entry test conditions. Even though the screening process will exclude non-laminar exit conditions in the near field of the present cavity flow fields, this screening does not preclude laminar exit conditions that transition to turbulence further downstream in the farfield, because the cavity does introduce instabilities that may continue to grow. Criteria for downstream transition to turbulence due to a cavity are discussed in Horvath, et al. ${ }^{10}$.

An example showing closed-cavity length $(L / H)$ effects on heating augmentation for laminar entry conditions is presented in the heating images shown in Figure 8a for $\mathrm{M}_{\mathrm{e}}=2.24, \mathrm{Re}_{\theta}=300$, and $H / \delta \approx 1.35$. The corresponding cavity centerline heating distributions are presented in Figure 8 b. Here, $L / H$ is systematically increased from 15.6 to 34.0 . For the case where $\mathrm{L} / \mathrm{H}=15.6$ just exceeds the classical lower-limit definition for closed flow, the cold floor is dominant with a hot endwall; only small effects are seen downstream, implying minimal disturbance to the surrounding flow. For $\mathrm{L} / \mathrm{H}=20.8$, the cold floor has barely changed based on the centerline heating profiles, the endwall is hotter, the cavity wake is pronounced, and the endwall shock/expansion system causes the flow to balloon outward and increase the heating around the side of the cavity. (Note, because of minimal differences the image for $\mathrm{L} / \mathrm{H}=18.2$ is not presented.) For $\mathrm{L} / \mathrm{H}=26.5$ and $\mathrm{L} / \mathrm{H}=34.0$, fully-developed flow at no-cavity laminar heating levels are observed on the cavity floor, large increases in the endwall occur, and the cavityinduced heating in the downstream wake is at the turbulent heating level.

The impact of planform-induced changes in open-cavity $(L / H=8)$ heating augmentation for laminar entry conditions is presented in the images in Figure 9a for $M_{e}=2.91, R_{\theta}=300$, and $\mathrm{H} / \delta=2$. The corresponding centerline distributions are presented in Figure $9 \mathrm{~b}$. Diamond, circular, and square planforms show virtually no heating augmentation differences in either the images or the linecuts. Each has a cold floor, a similar hot downstream endwall, and a minimal and very 
rapidly decaying wake. The linecuts support the observation that the flow skips the cavity as would be expected for open flow physics.

\section{Non-Laminar Data Screening}

As shown in Section V, laminar-entry/laminar-exit heating distributions are similar for open and closed cavity flow conditions. Any non-laminar in-cavity behavior is visually obvious as a deviation from the typical baseline heating profiles shown in Figure $8 \mathrm{~b}$ and Figure $9 \mathrm{~b}$. The extent of the downstream disturbance of a laminar-exit cavity is reflected in the decay of its heating wake. As developed in Ref. 8 , the heating from the laminar wake is conservatively approximated by

$$
\ln \left(\frac{B F-1}{B F_{M A X}-1}\right)=\frac{X_{M A X}-X}{H}
$$

where $X_{M A X}$ is the location of the maximum heating on the endwall, i.e. $B F_{M A X}$. Open-flow conditions demonstrating this are presented in Figure 10. Similarly, the closed-flow condition is presented in Figure 11. In both cases, laminar-exit heating augmentation recovers to the baseline undisturbed value approximately five cavity depths downstream of the peak. When the flow is transitional at the cavity exit, the downstream heating distributions deviate from this baseline as shown in Figure 12. Here, as is typical of transitional flow, the heating begins its rise from the laminar baseline toward turbulent heating values. An examination of the in-cavity behavior also shows the deviation from the laminar baseline. When the flow becomes turbulent, the downstream level is nominally 3 times the upstream laminar level. Turbulent heating distributions were demonstrated in Figure $8 \mathrm{~b}$ for closed cavities. The $\mathrm{L} / \mathrm{H}=26.5$ cavity flow exits transitional and becomes turbulent near $\mathrm{X} / \mathrm{L}=1.4$, while the $\mathrm{L} / \mathrm{H}=34$ cavity flow exits turbulent with a reduced heating due to the expansion around the endwall then assumes a heating decay to turbulent levels. Inside the cavity, the turbulent flow has significantly energized the heating, again altering those distributions. When non-laminar, this behavior was observed in all cases in the database.

\section{Summary of Laminar and Turbulent Bump Factor Correlations}

It was graphically demonstrated in Reference 8 that neither $B F_{A V G}$ nor $B F_{M A X}$ could be correlated with the individual primary test variables (e.g. $M_{e}, \operatorname{Re}_{\theta}, \operatorname{Re}_{\theta} / M_{e}, L / H, H / \delta, L / \delta$ ) for fully-laminar cavities. Accordingly, laminar correlation parameters were developed to collapse and quantify the variation of heating over a wide range of conditions for both open and closed cavity flow physics. Cavity heating correlation coefficients were specifically developed for the Mach 6 data and for the Mach 10 data, each independently to ensure consistency. The two data sets were then combined into a Mach 6/Mach 10 aggregate, providing a third set of coefficients. In each case the coefficients were very similar with the primary difference being the tighter

uncertainty bounds about the Mach 10 data. Scatter in data acquired at Mach 10 was smaller because the higher surface temperatures resulted in lower uncertainties. The correlation parameters are given by 


$$
\begin{aligned}
& X=\ln \left[M_{e}^{\sigma} \operatorname{Re}_{\theta}^{\tau}\left(\frac{L}{\delta}\right)\right] \\
& Y=\ln \left[\left(\frac{H}{\delta}\right)^{\alpha}\left(1+\frac{L}{H}\right)^{\beta} B F\right]
\end{aligned}
$$

The powers $\alpha, \beta, \sigma$, and $\tau$ were iteratively prescribed in spreadsheet software to maximize the $\mathrm{R}^{2}$ statistic. Power coefficients are presented in Table 3.

The correlation parameters for $B F_{A V G}$ and $B F_{M A X}$ defined using Eq. 2 were next input to the commercially available SYSTAT TableCurve $2 D$ program to establish the mathematical relationships for the heating variations. The coefficients $a$ and $b$ in the linear (in transformed loglog space) correlation curve

$$
Y=a+b X
$$

were determined by the program. Coefficients for the Mach 6/Mach 10 aggregate data set are presented in Table 3; coefficients for the individual Mach 6 and Mach 10 data sets are found in Ref. 8. Output from the program included upper and lower confidence limits (UCL and LCL, respectively) on the curve coefficients and the linear correlation coefficient, $\mathrm{R}^{2}$, as statistical measures of the goodness-of-fit to the data. Confidence limits are a measure of the uncertainty in the average value of a coefficient drawn from an existing population. The linear correlation coefficient measures how well the data fit a linear mathematical model, with $\mathrm{R}^{2}=1$ providing a perfect fit. The program also provides upper and lower prediction limits (UPL and LPL, respectively) which measure the ability of the curve to estimate the value of a future observation obtained from the population. By statistical necessity, prediction limits must be wider than confidence limits to capture the additional uncertainty carried by the new data. A discussion of these statistical concepts is provided in Morrison $^{27}$.

Results of the heating correlation development process for laminar baseline-geometry cavities are presented in Figure 13. Correlations for the $B F_{A V G}$ and $B F_{M A X}$ are provided in figures (a) and (b), respectively. Open symbols represent open cavities; closed symbols represent closed cavities. Red circles are the Mach 6 data; blue squares are the Mach 10 data. A major finding for laminar cavities was the collapse of the open and closed cavity heating variations into a singlecurve parameterization for each of the $B F_{A V G}$ and $B F_{M A X}$ metrics. The application of the correlations to non-baseline geometries simulating random impact damage is also presented in Ref. 8. Heating augmentation predictions for these cases fall within the $99 \%$ upper and lower prediction limits established for laminar rectangular baseline-geometry correlations. For clarity, only the correlation curves for the aggregate Mach 6/Mach 10 dataset will be presented for comparison in subsequent figures.

The laminar-entry/laminar-exit heating correlations (Eq. 2) were extended in Ref. 9 to cover fully turbulent flow conditions using closed-cavity data acquired in Ref. 2 and open-cavity data acquired from the open literature (see Ref. 9). Turbulent correlation coefficients and powers are presented in Ref. 9. Unlike the laminar correlations, separate open and closed correlations were required for the turbulent flow cases. 


\section{Correlation of In-Cavity Transition and Heating Augmentation}

Transitional cavity heating data were identified in the database using the process described in Section VI. The laminar Mach 6/Mach 10 correlation parameters (Eqs. 2, Table 3, and Table 4) were applied to $B F_{A V G}$ and $B F_{M A X}$, and the results are plotted in Figure 14 and Figure 15, respectively, as $\left(X_{A V G}, Y_{A V G}\right)$ and $\left(X_{M A X}, Y_{M A X}\right)$. The fully-laminar Mach 6/Mach 10 correlations are provided for reference. Plotting nomenclature is as presented in Section VII. All data presented in these figures were acquired during flat plate cavity experiments presented in Section III and are unused in any other analysis, exclusive of the data reduction and screening processes. A perceptible deviation to a non-laminar cavity condition is observed near 3.5 for both $X_{A V G}$ and $X_{M A X}$. This non-laminar deviation increases until turbulent cavity exit conditions are achieved and then the deviation continues parallel to the corresponding laminar correlation curve, consistently matching or exceeding the 99\% Upper Uncertainty Prediction Limits. Recall that a laminar upstream reference is used to normalize the local heating to generate the $B F$. Therefore, the increase represents energy augmentation attributable to increased flow mixing and shearing in and downstream of the cavity.

Distributions of the non-laminar increments in the $B F$ are obtained by subtracting the appropriate laminar correlation from the data. Accordingly, $\Delta Y_{t r, A V G}$ and $\triangle Y_{t r, M A X}$ are developed and plotted in Figure 16 and Figure 17, respectively. Cavity transition results from the Mach 6 and 10 are coincident and scatter uniformly. Since the laminar baseline has been removed, the limited, new laminar data were also removed below $X_{A V G}=2.7$ and $X_{M A X}=2.5$ using engineering judgment, and also because these data lie well within the expected laminar region. Then, dummy values of $Y_{A V G}=0$ and $Y_{M A X}=0$ were provided in $0.1 X_{A V G}$ and $X_{M A X}$ increments to ensure a proper functional behavior for fitting the transitional data. Again using the SYSTAT TableCurve 2D program, a best fit to the data was provided using the following mathematical expression.

$$
\Delta Y_{t r}=\frac{a}{1+\exp \frac{-\left(X-X_{0}\right)}{b}}
$$

The defining coefficients $a, b$, and $X_{0}$ are presented in Table 5. A degrees-of-freedom adjusted (DFAdj) $R^{2}=0.86$ is achieved for $\triangle Y_{t r, A V G}$ and a $D F A d j R^{2}=0.81$ is achieved for $\triangle Y_{t r, M A X}$. The lower $D F A d j R^{2}$ for the endwall is reflective of a point measurement, instead of an average value. The plotted $95 \%$ confidence and prediction limit curves are highly descriptive of the curve fit and the scatter in the data.

Letting $\left[-\left(x-x_{0}\right) / b\right]$ assume values of \pm 3 yields $\Delta Y_{t r} / a$ of 0.0474 and 0.9526 , respectively.

This provides a transition region deviating approximately 5\% from the laminar correlation on the low end and extending to $95 \%$ of a fully effective tripped turbulent flow condition exiting the cavity on the high end. Using the curve-fit values taken from Table 5 provides a floor-based transition region for $\Delta Y_{t r, A V G}$ extending from $X_{t r, A V G}=3.0$ to 5.2 and an endwall-based transition region for $\triangle Y_{t r, M A X}$ extending from $X_{t r, M A X}=2.3$ to 4.6. These limits on $X_{t r, A V G}$ and $X_{t r, M A X}$ effectively define the upper application bounds of the laminar heating correlations; however, the user of the in-cavity transition model must define transition onset, whether the upper or lower bounds of the $X_{t r}$ are used or whether the mid-point, $X_{0}$, is used. 


\section{Correlation Validation using 0.75-Percent-Scale Shuttle Model Data}

Horvath, et al. ${ }^{10}$ acquired cavity-induced boundary layer transition data on the Shuttle windward (lower) surface in support of the CAIB and RTF programs at Mach 6 in air and $\mathrm{CF}_{4}$, and at Mach 10 in air. As with the current cavity heating experiments, global phosphor thermography was used to measure surface temperatures that were converted to heating. Even though the emphasis was on the downstream transition effects, measurements on the floor of the larger cavities (see Table 2) tested were of sufficient resolution that heating averages could be obtained as a by-product. Unfortunately, even with the largest of the cavities, the relatively large camera pixels averaged the high-gradient endwall heating such that the important peak values are missed and the measurements are heavily biased. The largest cavity contained only 4-6 pixels from the endwall floor to the over-expansion heating bucket downstream of the endwall. Similarly, the floor of the smallest cavities may contain as few as 4-6 pixels, and these could be spread over the sidewalls. Therefore, only $B F_{A V G}$ results are presented for the larger cavities.

Shuttle cavity heating correlation parameters were developed using Eqs. (2), and each test is individually compared with the flat plate Mach 6/Mach 10 cavity heating correlation curves in Figure 18 for Mach 10 Air, in Figure 19 for Mach $6 \mathrm{CF}_{4}$, and in Figure 20 for Mach 6 Air. Individually, the Shuttle cavity data offer an additional validation of the flat-plate-derived expressions for heating augmentation. The data also indicate the previously noted non-laminar deviation near $X_{A V G}=3.5$.

An aggregate plot of all Shuttle cavity data demonstrating within test and tunnel-to-tunnel consistency is presented in Figure 21. Based on this figure, the $Y_{A V G}$ (i.e. $B F_{A V G}$ ) is at least firstorder insensitive to changes in $\mathrm{M}_{\infty}$ and $\gamma$. Similarly, the flow turning angle into the cavity will exhibit the same independency, since $Y_{A V G}$ is independent of $M_{e}(\sigma=0$, see Table 3). Therefore, Figure 21 also implies that the laminar definition of open and closed cavity boundaries should be unchanging to at least first order during vehicle re-entry. The question posed in References 2 and 8 (for example) regarding the impact of $\gamma$ on $Y_{M A X}$ remains open.

Following the development outlined in Section VIII, the trend of the Mach 6/Mach 10 laminar flat-plate-developed correlation curve is removed from the Shuttle data to generate the $\Delta Y_{t r, A V G}$. The result is plotted in Figure 22 where data scatter randomly about the transitional heating correlation within the $\pm 95 \%$ prediction limit curves. The results offer clear validation evidence for the cavity-heating augmentation increment due to boundary layer transition, and they substantiate the in-cavity boundary layer transition onset predictions. These results clearly demonstrate the above-cited $\gamma$ independency.

\section{Application Example}

Application of the transition correlation is straightforward, and the specific application at the transition region limits enables simple analysis relationships. Recalling that $\Delta Y_{t r}$ is the difference between the transitional heating parameter and the laminar heating parameter yields equation (5).

$$
\Delta Y_{t r}=Y_{t r}-Y_{\text {Lam }}=\ln \left(\frac{B F_{t r}}{B F_{\text {Lam }}}\right)
$$

The limits of the transition region are, again, obtained by setting the argument of the exponential in equation (4) to \pm 3 , yielding equation (6).

$$
X=X_{0} \mp 3 b
$$


The conditions providing probable transition onset on the cavity floor are next computed using equations (2) and (6), and laminar correlation coefficients from Table 3. Thus,

$$
\begin{aligned}
& X_{t r, \text { Lam }}=4.109-3(0.366)=3.01 \\
& \ln \left(\operatorname{Me}^{0} \operatorname{Re}_{\theta}^{0.1} \frac{L}{\delta}\right)=3.01 \\
& \frac{M e^{0} \operatorname{Re}_{\theta}^{0.1}}{\delta}=\frac{e^{3.01}}{L}=\frac{20.31}{L}
\end{aligned}
$$

The conditions providing probable completion of transition on the cavity floor that occur when fully turbulent flow exits the cavity are next computed using equations (2) and (6), and coefficients from Table 3.

$$
\begin{aligned}
& X_{t r, T u r b}=4.109+3(0.366)=5.21 \\
& \ln \left(\operatorname{Me}^{0} \operatorname{Re}_{\theta}^{0.1} \frac{L}{\delta}\right)=5.21 \\
& \frac{M e^{0} \operatorname{Re}_{\theta}^{0.1}}{\delta}=\frac{e^{5.21}}{L}=\frac{183.09}{L}
\end{aligned}
$$

Accordingly, transitional flow within the cavity is expected when boundary layer entrance conditions and cavity length satisfy the relationship

$$
\frac{20}{L}<\left(\frac{\operatorname{Re}_{\theta}^{0.1}}{\delta}\right)_{A V G}<\frac{183}{L}
$$

Note that longer cavities provide enhanced possibilities for transition onset, as would be expected because of the increased disturbance. Also as expected, thicker boundary layers reduce the possibility of transition because the cavity becomes buried under a protective layer. Shallower, less-intrusive cavities are reflected in the non-dimensional cavity depth $\mathrm{H} / \delta$ as the boundary layer thickens. The lower boundary in relationship (9) provides the upper application limit for the fully laminar cavity floor heating correlation. The upper boundary provides the condition for fully effective boundary layer tripping by the cavity.

Next, augmented heating on the cavity floor can be compute using equation (5) and coefficient values taken from Table 5. At transition onset

$$
\begin{aligned}
& \Delta Y_{t r, \text { Lam }}=\frac{2.57}{1+e^{3}}=0.122 \\
& \left(\frac{B F_{t r, \text { Lam }}}{B F_{\text {Lam }}}\right)_{A V G}=e^{0.122}=1.13
\end{aligned}
$$

providing a $13 \%$ increase above the laminar heating level. At transition completion 


$$
\begin{aligned}
& \Delta Y_{t r, T u r b}=\frac{2.57}{1+e^{-3}}=2.448 \\
& \left(\frac{B F_{t r, T u r b}}{B F_{\text {Lam }}}\right)_{A V G}=e^{2.448}=11.56
\end{aligned}
$$

The existence of turbulent exit flow provides a factor of 12 increase in the heating augmentation on the floor above the laminar baseline.

Finally, the transition region for the endwall maximum values are similarly obtained using Table 5. Note that the local Mach number must now be included in the endwall relationship.

$$
\frac{10}{L}<\left(\frac{M e^{0.2} \operatorname{Re}_{\theta}^{0.05}}{\delta}\right)_{M A X}<\frac{98}{L}
$$

The lower boundary of (12) provides the upper application boundary for the fully laminar cavity endwall heating correlation.

As developed above for the floor, limits on the transitional endwall heating augmentation are provided by

$$
\begin{aligned}
& \left(\frac{B F_{\text {tr, Lam }}}{B F_{\text {Lam }}}\right)_{\text {MAX }}=1.06 \\
& \left(\frac{B F_{\text {tr,Turb }}}{B F_{\text {Lam }}}\right)_{\text {MAX }}=3.03
\end{aligned}
$$

A $6 \%$ heating increase above the laminar baseline is indicated in the peak endwall heating at transition onset, while a factor of 3 increase occurs for peak endwall heating when fully-effective tripping occurs at the exit.

\section{Concluding Remarks}

Previously unused, laminar-entry cavity heating data with a non-laminar boundary layer exit flow have been retrieved from the database developed for the Space Shuttle Return-To-Flight Program. These data were acquired at Mach 6 and 10 in air on large flat plate models to support tool development for impact damage assessment of the Orbiter thermal protection system. This database provides the basis of the current laminar analysis methods that are incorporated into the Cavity Heating Tool (Version 3).

Building on previously published fully laminar and fully turbulent analysis methods, new descriptive correlations of the in-cavity floor-averaged heating and endwall maximum heating have been developed for laminar-entry conditions with transitional-to-turbulent exit flow. These new local-cavity correlations provide the expected flow and geometry conditions for transition onset; they provide the incremental heating augmentation induced by transitional flow; and, they provide the transitional-to-turbulent exit cavity length. Furthermore, they provide an upper application limit for the previously developed fully-laminar heating correlations.

An application example has been presented to illustrate the simplicity of implementation as an analysis tool. If cavity length and flow conditions are sufficient to introduce fully effective tripping to turbulent flow at its exit, the example shows that a factor of 12 heating augmentation 
can be expected on the cavity floor. The example also shows that a corresponding factor of 3 heating augmentation can be expected for the cavity endwall maximum.

Cavity floor heating data in small-scale geometries installed on the windward surface of 0.075-scale Shuttle wind tunnel models have been retrieved from the boundary layer transition database developed for the RTF program. These data were independently acquired at Mach 6 and Mach 10 in air, and at Mach 6 in $\mathrm{CF}_{4}$. The correlation parameters for the floor-averaged heating have been developed and they offer an exceptionally positive comparison to the previously developed laminar heating correlations. Non-laminar increments have been extracted from these Shuttle data and they fall on the newly developed transitional in-cavity correlations and are bounded by the correlation $\pm 95 \%$ prediction limits. No cavity-heating-augmentation differences were observed between the air $(\gamma=1.4)$ and the $\mathrm{CF}_{4}(\gamma=1.1)$ experiments.

\section{References}

\footnotetext{
${ }^{1}$ Report of the Columbia Accident Investigation Board, Vol. 1, National Aeronautics and Space Administration, August 2003.

${ }^{2}$ Everhart, Joel L., Berger, Karen T., Brauckmann, Gregory J, Merski, N. Ronald, and Wood, William A., "Parametric Cavity Heating Experiments Supporting Shuttle Orbiter Return To Flight,” NASA JSC EG-SS-06-04, 2007.

${ }^{3}$ Everhart, Joel L., Berger, Karen T., Bey, Kim S., Merski, N. Ronald, and Wood, William A., "Cavity Heating Experiments Supporting Shuttle Columbia Accident Investigation,” NASA TM 2011-214528, 2011.

${ }^{4}$ Everhart, Joel L., Alter, Stephen J., Merski, N. Ronald, Wood, William A., and Prabhu, Ramadas K., "Pressure Gradient Effects on Hypersonic Cavity Flow Heating," AIAA 2006-0185, Presented at 44th AIAA Aerospace Sciences Meeting and Exhibit, Reno, NV, January 9-12, 2006.

${ }^{5}$ Everhart, Joel L., Berger, Karen T., Merski, N. Ronald, Wood, William A., Hollingsworth, Kevin E., Hyatt, Andrew J., and Prabhu, Ramadas K., "Aero-Heating of Shallow Cavities in Hypersonic Freestream Flow,” NASA JSC EG-SS-06-07, 2007.

${ }^{6}$ Everhart, Joel L., Hollingsworth, Kevin E., Erickson, David W., Merski, N. Ronald, and Prabhu, Ramadas K., "Real Cavity Heating Experiments Supporting Shuttle Orbiter Return To Flight,” NASA JSC EG-SS-07-01, 2007

${ }^{7}$ Anderson, Brian, Hyatt, Jay, Wang, K.C., Everhart, Joel, Greene, Frank, Pulsonetti, Maria, Wood, Bill, Bourland, Gary, and Cassady, Amy, “The Cavity Heating Tool,” Boeing Technical Memorandum ATA-AH-TM-2005-079, The Boeing Company, NASA Space Systems, Houston, TX, Dec. 7, 2005.

${ }^{8}$ Everhart, Joel L., "Supersonic/Hypersonic Laminar Heating Correlations for Rectangular and Impact-Induced Open and Closed Cavities," Journal of Spacecraft and Rockets, Volume 48, Number 3, pp. 545-560, 2009. (Also, AIAA 2008-1283, Presented at 46th AIAA Aerospace Sciences Meeting and Exhibit, Reno, NV, January 7-10, 2008.)

${ }^{9}$ Everhart, Joel L. and Green, Francis A.: Turbulent Supersonic/Hypersonic Heating Correlations for Open and Closed Cavities. Journal of Spacecraft and Rockets, Vol. 47, No. 4, Jul.-Aug. 2010, pp. 545-553.

${ }^{10}$ Horvath, Thomas J., Berry, Scott. A., Merski, N. Ronald, Berger, Karen T., Buck, Gregory M., Liechty, Derek S., and Schneider, Steven P., "Shuttle Damage/Repair from the Perspective of Hypersonic Boundary Layer Transition - Experimental Results.” AIAA Paper 2006-2919, June 2006.

${ }^{11}$ Micol, J.R., "Langley Aerothermodynamic Facilities Complex, Enhancements and Testing Capabilities," AIAA Paper 980147, January 1998.

${ }^{12}$ Charwat, A.F., Roos, J.N., Dewey, C.F., Jr., and Hitz, J.A., “An Investigation of Separated Flows - Part I, The Pressure Field,” Journal of Aerospace Sciences, Vol. 28, No. 6, June 1961, pp. 457-470.

${ }^{13}$ Charwat, A.F., Dewey, C.F., Roos, J.N., and Hitz, J.A., "An Investigation of Separated Flows - Part II, Flow in the Cavity and Heat Transfer," Journal of Aerospace Sciences, Vol. 28, No. 7, pp. 513-527, July 1961.

${ }^{14}$ Berry, Scott. A., Horvath, Thomas J., Greene, Francis A., Kinder, Gerald R., and Wang, K. C., "Overview of Boundary Layer Transition Research in Support of Orbiter Return To Flight.” AIAA Paper 2006-2918, June 2006.

${ }^{15}$ Stallings, Robert L., Jr., Wilcox, Floyd J., Jr., and Forrest, Dana K., "Measurements of Forces, Moments, and Pressures on a Generic Store Separating From a Box Cavity at Supersonic Speeds,” NASA TP 3110, Sept. 1991.

${ }^{16}$ Merski, N.R., "Global Aeroheating Wind Tunnel Measurements Using Improved Two-Color Phosphor Thermography Method," Journal of Spacecraft and Rockets, Vol. 36, No. 2, 1999, pp. 160-170.

17 Merski, N.R., "Global Aeroheating Wind Tunnel Measurements Using Improved Two-Color Phosphor Thermography Method," Journal of Spacecraft and Rockets, Vol. 36, No. 2, 1999, pp. 160-170.

${ }^{18}$ Hollis, B.R., "Real-Gas Flow Properties for NASA Langley Research Center Aerothermodynamic Facilities Complex Wind Tunnels," NASA CR 4755, September 1996.

${ }^{19}$ Berry, S.A., Difulvio, Michael, and Kowalkowski, Matthew K., "Forced Boundary-Layer Transition on X-43 (Hyper-X) in NASA LaRC 20-Inch Mach 6 Air Tunnel.” NASA TM-2000-210316, Aug.2000.
} 
${ }^{20}$ Berry, S.A., Auslender, A.H., Dilley, A.D., and Calleja, J.J., "Hypersonic Boundary-Layer Trip Development for Hyper-X," Journal of Spacecraft and Rockets, Volume 38, Number 6, pp. 853-864, 2001.

${ }^{21}$ Buck, G.M., and Vasques, P., "An Investment Ceramic Slip-Casting Technique for Net-Form, Precision, Detailed Casting of Ceramic Models," U.S. Patent 5,266,252, November 1993.

${ }^{22}$ Buck, G.M., Powers, M.A., Nevins, S.C., Griffith, M.S., Verneris, P.H., and Wainwright, G.A., "Rapid Fabrication of Flat Plate Cavity Phosphor Thermography Test Models for Shuttle Return-to-Flight Aero-Heating," NASA TM 2006-214508.

${ }^{23}$ Merski, N.R., "An Improved Two-Color Relative-Intensity Phosphor Thermography Method for Hypersonic Wind Tunnel Aeroheating Measurements,” NASA CDTP-1017, February 2001.

${ }^{24}$ Campbell, Charles H., Wang, K. C., An, Michael Y., Tam, Luen T., Bouslog, Stanley A., “Orbiter Boundary-Layer Working Group, Numerical Flow Field Analysis Data," JSC-26816, December, 1994.

${ }^{25}$ Gnoffo, P.A., Gupta, R.N., and Shinn, J.L., "Conservation Equations and Physical Models for Hypersonic Air Flows in Thermal and Chemical Nonequilibrium,” NASA TP 2867, February 1989.

${ }^{26}$ Gnoffo, P.A., An Upwind-Biased, Point-Implicit Relaxation Algorithm for Viscous, Compressible Perfect Gas Flows,” NASA TP 2953, February 1990.

${ }^{27}$ Morrison, Donald F., “Applied Linear Statistical Methods,” Prentice-Hall, Inc., Englewood Cliffs, New Jersey, 1983.

\section{Tables}

Table 1.- Test parameter ranges at cavity entrance.

\begin{tabular}{lcc}
\hline \hline Parameter & Flat Plate Range & Shuttle Model Range \\
\hline$M_{e}$ & 1.75 to 3.20 & 1.31 to 2.53 \\
$R e_{\theta}$ & 150 to 725 & 43 to 348 \\
$R e_{\theta} / M_{e}$ & 60 to 340 & 33 to 137 \\
$L / H$ & 7 to 30 & 2.5 to 21 \\
$H / \delta$ & 0.1 to 2.4 & 0.4 to 4.7 \\
$L / \delta$ & 0.5 to 40 & 3.4 to 54 \\
\hline \hline
\end{tabular}

Table 2.- Cavity dimensions for 0.75-percent Shuttle model.

\begin{tabular}{lllllll}
\hline \hline & Model & L (in) & W (in) & H (in) & L/H & W/H \\
\hline Baseline & C01 & 0.074 & 0.071 & 0.0300 & 2.47 & 2.37 \\
& C02 & 0.157 & 0.078 & 0.0300 & 5.23 & 2.60 \\
& C03 & 0.217 & 0.071 & 0.0297 & 7.31 & 2.39 \\
& C04 & 0.299 & 0.072 & 0.0300 & 9.97 & 2.40 \\
& C05 & 0.445 & 0.072 & 0.0350 & 12.71 & 2.06 \\
& C06 & 0.602 & 0.072 & 0.0340 & 17.71 & 2.12 \\
\hline Depth & C07 & 0.218 & 0.072 & 0.0423 & 5.15 & 1.70 \\
Excursion & C08 & 0.218 & 0.072 & 0.0210 & 10.38 & 3.43 \\
& C09 & 0.453 & 0.073 & 0.0460 & 9.85 & 1.59 \\
& C10 & 0.451 & 0.071 & 0.0220 & 20.5 & 3.23 \\
\hline Width & C11 & 0.220 & 0.047 & 0.0300 & 7.33 & 1.57 \\
Excursion & C12 & 0.218 & 0.096 & 0.0330 & 6.61 & 2.91 \\
& C13 & 0.448 & 0.046 & 0.0290 & 15.45 & 1.59 \\
& C14 & 0.449 & 0.096 & 0.0310 & 14.48 & 3.10 \\
\hline \hline
\end{tabular}


Table 3.- Laminar cavity correlation coefficient powers.

\begin{tabular}{lcc}
\hline \hline Power & $\mathrm{BF}_{\mathrm{AVG}}$ & $\mathrm{BF}_{\mathrm{MAX}}$ \\
\hline$\alpha$ & 3.30 & 3.30 \\
$\beta$ & 2.70 & 3.70 \\
$\sigma$ & 0.00 & 0.20 \\
$\tau$ & 0.10 & 0.05 \\
\hline \hline
\end{tabular}

Table 4. Laminar cavity correlation coefficients for $y=a+b x$ fit of Mach 6/Mach 10 baseline data.

\begin{tabular}{lcccc}
\hline \hline & \multicolumn{2}{c}{$\mathrm{BF}_{\mathrm{AVG}}$} & \multicolumn{2}{c}{$\mathrm{BF}_{\mathrm{MAX}}$} \\
\cline { 2 - 5 } & $\mathrm{a}$ & $\mathrm{b}$ & $\mathrm{a}$ & $\mathrm{b}$ \\
\hline Correlation & -3.1703 & 3.0060 & -0.2038 & 3.6977 \\
$95 \% \mathrm{UCL}$ & -3.9370 & 3.0048 & -0.1129 & 3.6989 \\
$95 \%$ UPL & -2.5960 & 3.0058 & 0.5263 & 3.6979 \\
$99 \%$ UCL & -3.0693 & 3.0044 & -0.0838 & 3.6993 \\
$99 \%$ UPL & -2.4126 & 3.0058 & 0.7593 & 3.6979 \\
$99.9 \%$ UCL & -3.0388 & 3.0030 & -0.0475 & 3.6984 \\
$99.9 \%$ UPL & -2.1966 & 3.0055 & 1.0339 & 3.6978 \\
\hline \hline
\end{tabular}

For $\mathrm{BF}_{\mathrm{AVG}}$, $\mathrm{DFAdjR}^{2}=0.9886$ for $\mathrm{BF}_{\mathrm{MAX}}, \mathrm{DFAdjR}^{2}=0.9877$

Table 5. Cavity boundary layer transition correlation coefficient coefficients.

\begin{tabular}{lcc}
\hline \hline \multirow{2}{*}{$\Delta Y_{t r}=\frac{a}{1+\exp \frac{-\left(X-X_{0}\right)}{b}}$} \\
\hline \hline \multirow{2}{*}{ Coefficient } & Floor & Endwall \\
& Average & Centerline \\
& Peak \\
\hline$a$ & 2.57099 & 1.16378 \\
$X_{0}$ & 4.10882 & 3.44541 \\
$b$ & 0.36548 & 0.37928 \\
$R^{2}$ & 0.86015 & 0.80545 \\
\hline \hline
\end{tabular}




\section{Figures}
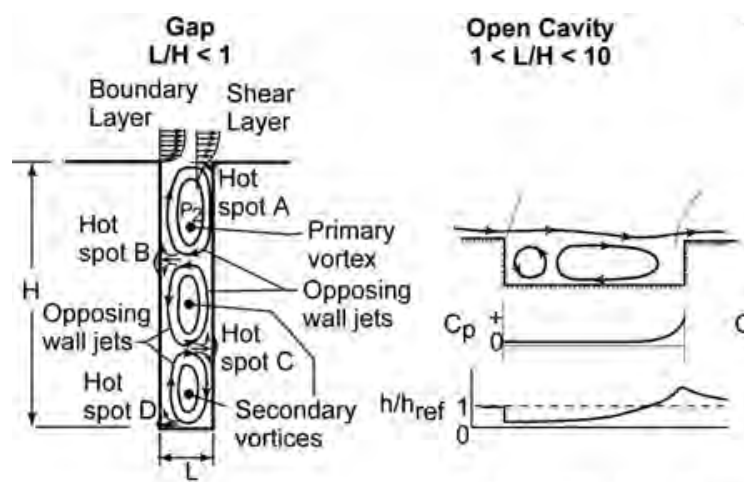

- Extensive data

- Stable flow solution - Representative laminar and turbulent flow data

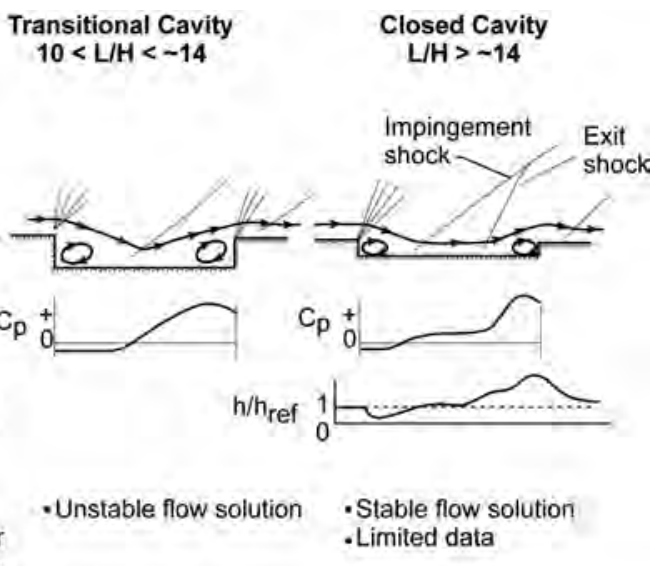

Figure 1. Cavity flow regimes.

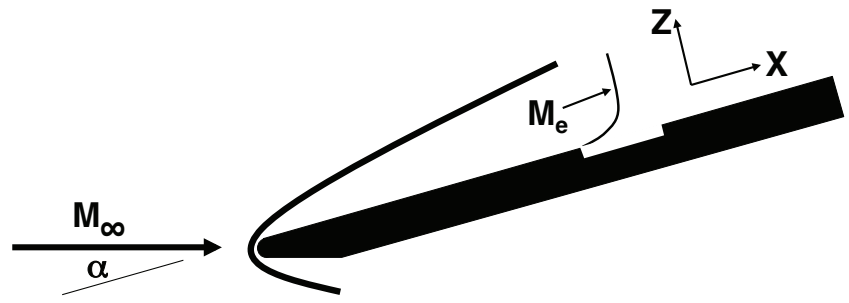

Figure 2. Model coordinate system.

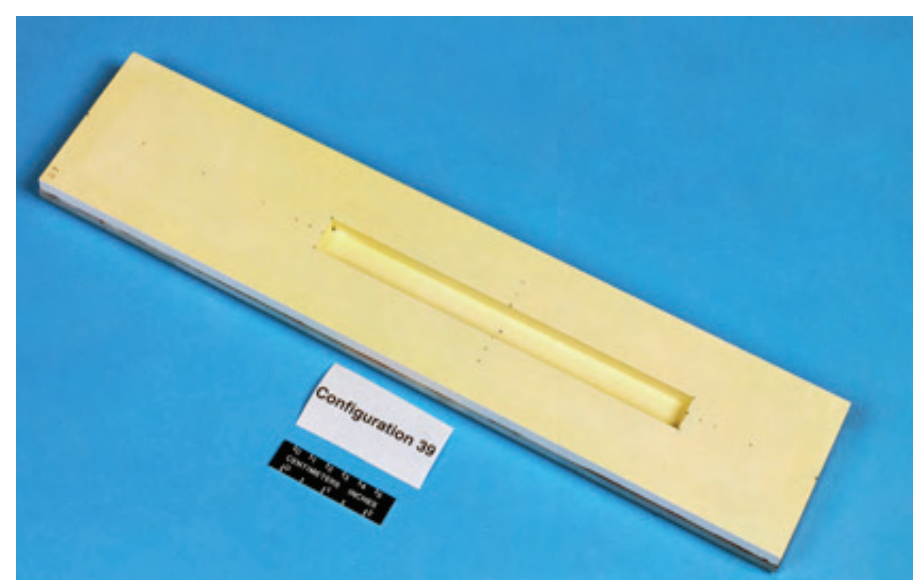

Figure 4. Sample cavity insert model.

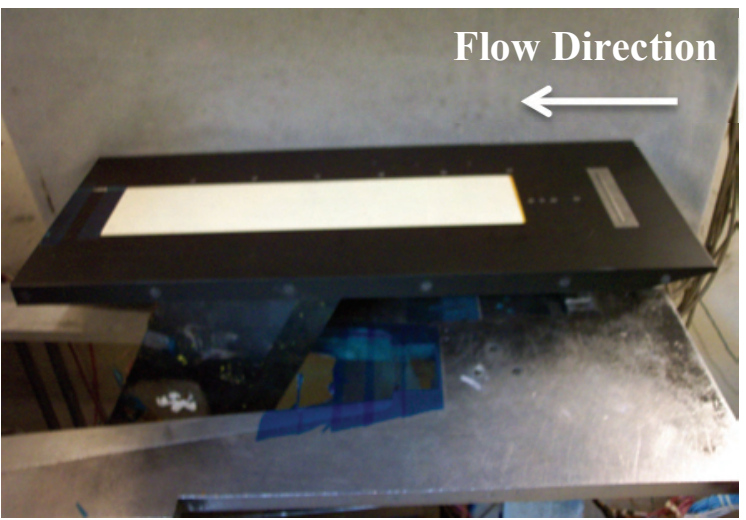

Figure 3. Baseline model with 4 -inch by 18 -inch ceramic insert.

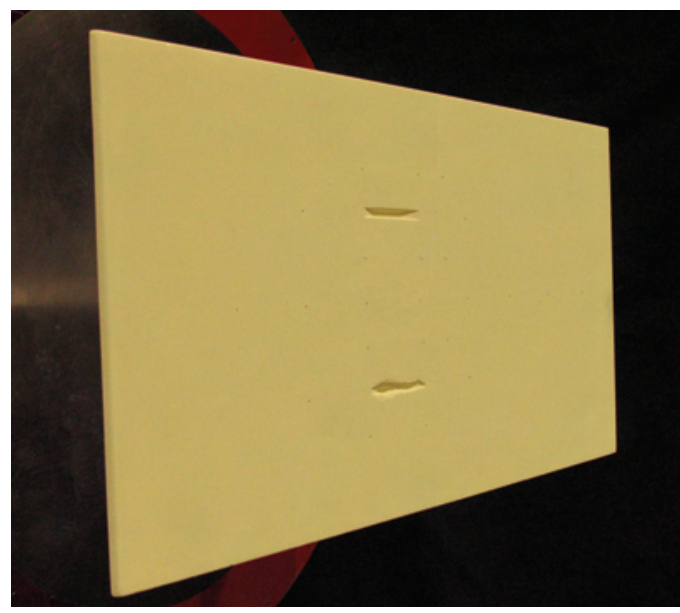

Figure 5. Full-surface ceramic model used in Mach 10 testing. 


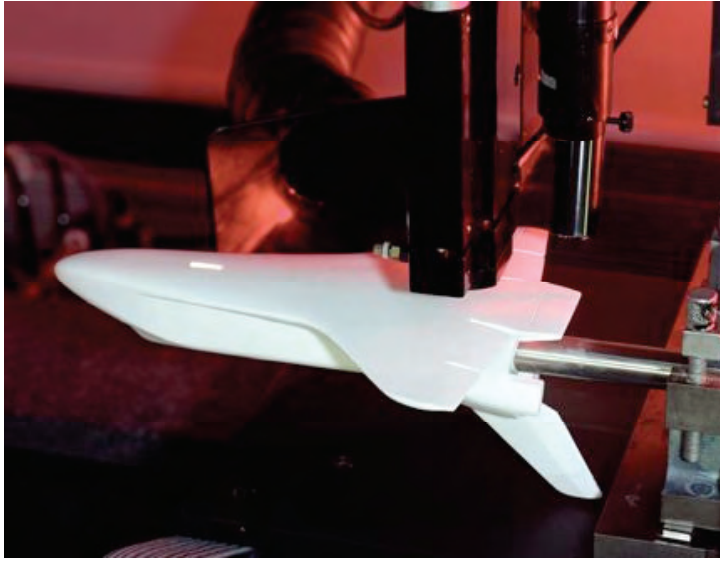

Figure 6. Laser ablation of Shuttle models.
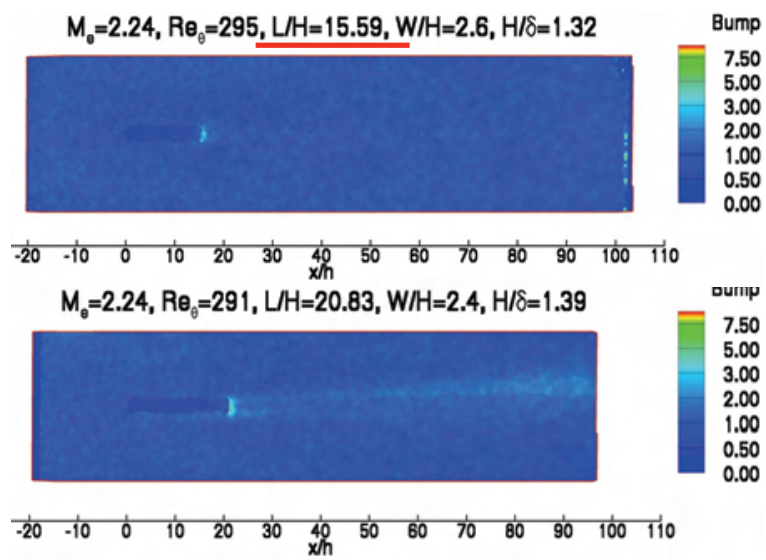

$M_{\theta}=2.24, R \theta_{\theta}=295, L / H=26.52, W / H=2.4, H / \delta=1.40$

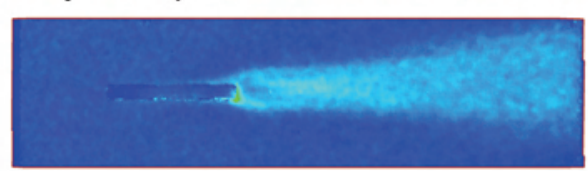

$\begin{array}{cccccccccccccc}-20 & -10 & 0 & 10 & 20 & 30 & 40 & 50 & 60 & 70 & 80 & 90 & 100 & 110\end{array}$
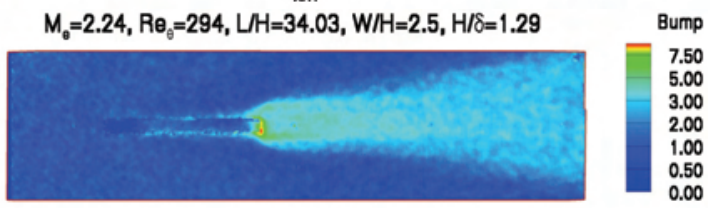

$\begin{array}{llllllllllllll}-20 & -10 & 0 & 10 & 20 & 30 & \frac{40}{40} & 50 & 60 & 70 & 80 & 90 & 100 & 110\end{array}$

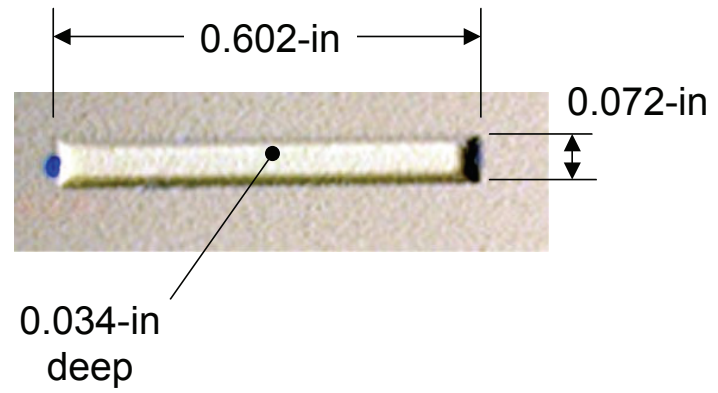

Figure 7. Typical large Shuttle cavity, $\mathrm{L} / \mathrm{H}=17.7$.

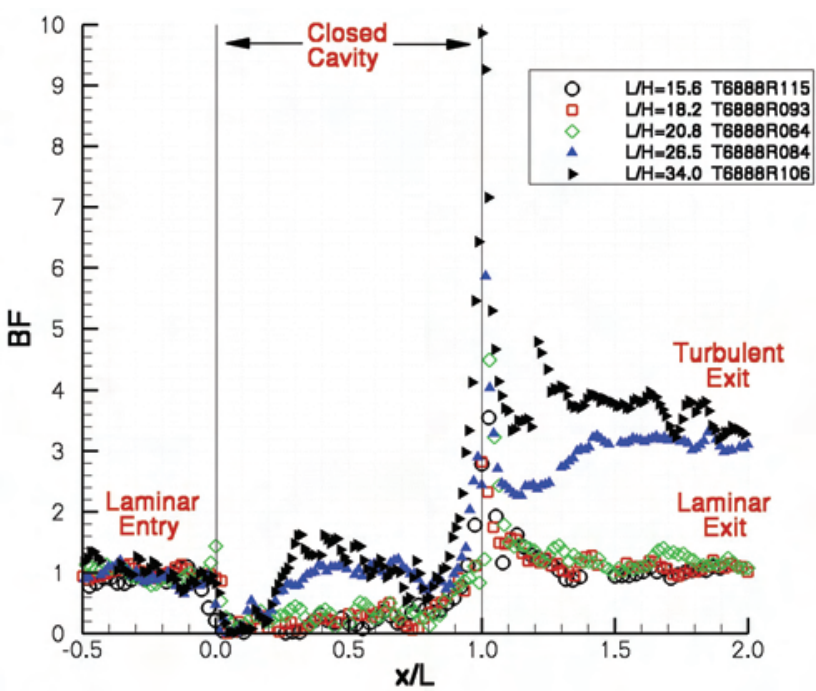

b) Centerline data.

a) Image data.

Figure 8. Closed-cavity length effect on heating for laminar-entry. $M_{e}=2.24, \operatorname{Re}_{\theta}=300$, $\mathrm{H} / \delta=1.35$. 


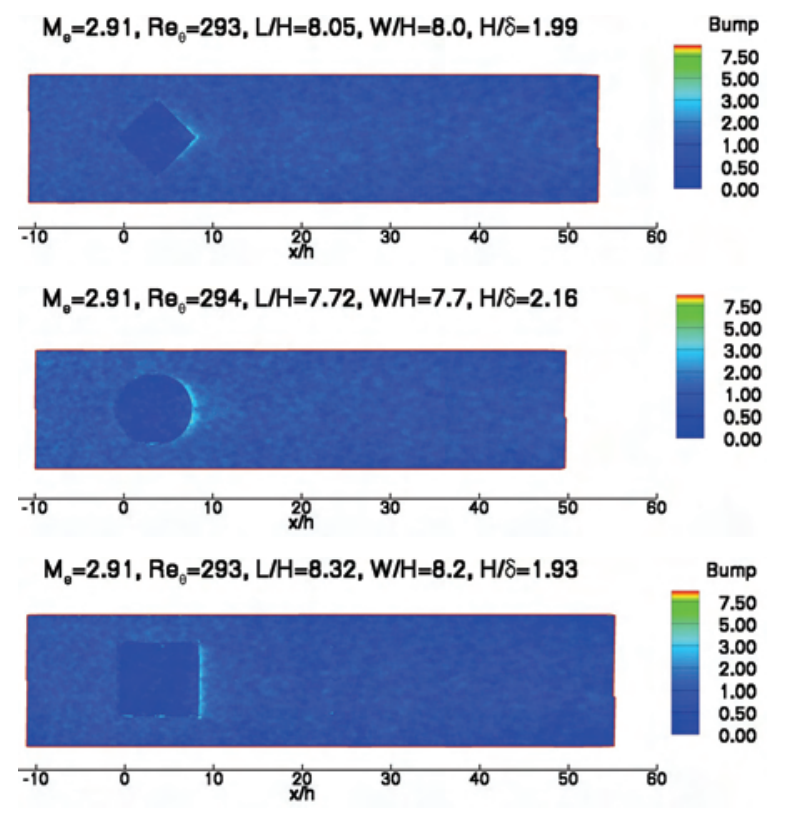

a) Image data.

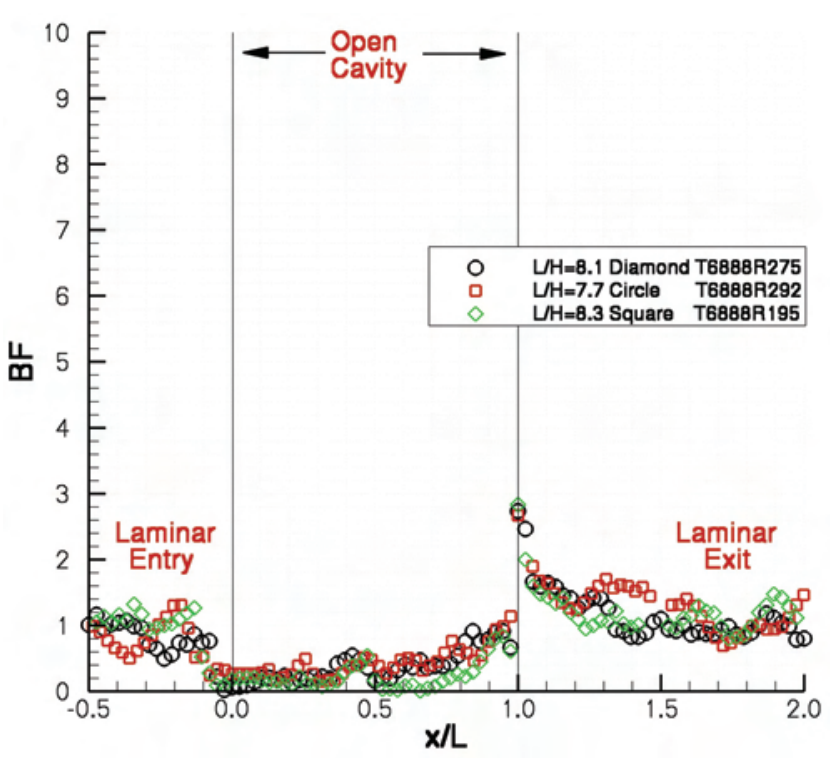

b) Centerline data.

Figure 9. Planform effect on open-cavity heating for laminar-entry. Test $6888, \mathrm{M}_{\mathrm{e}}=2.91, \mathrm{Re}_{\theta}=$ $300, \mathrm{H} / \delta=2$.

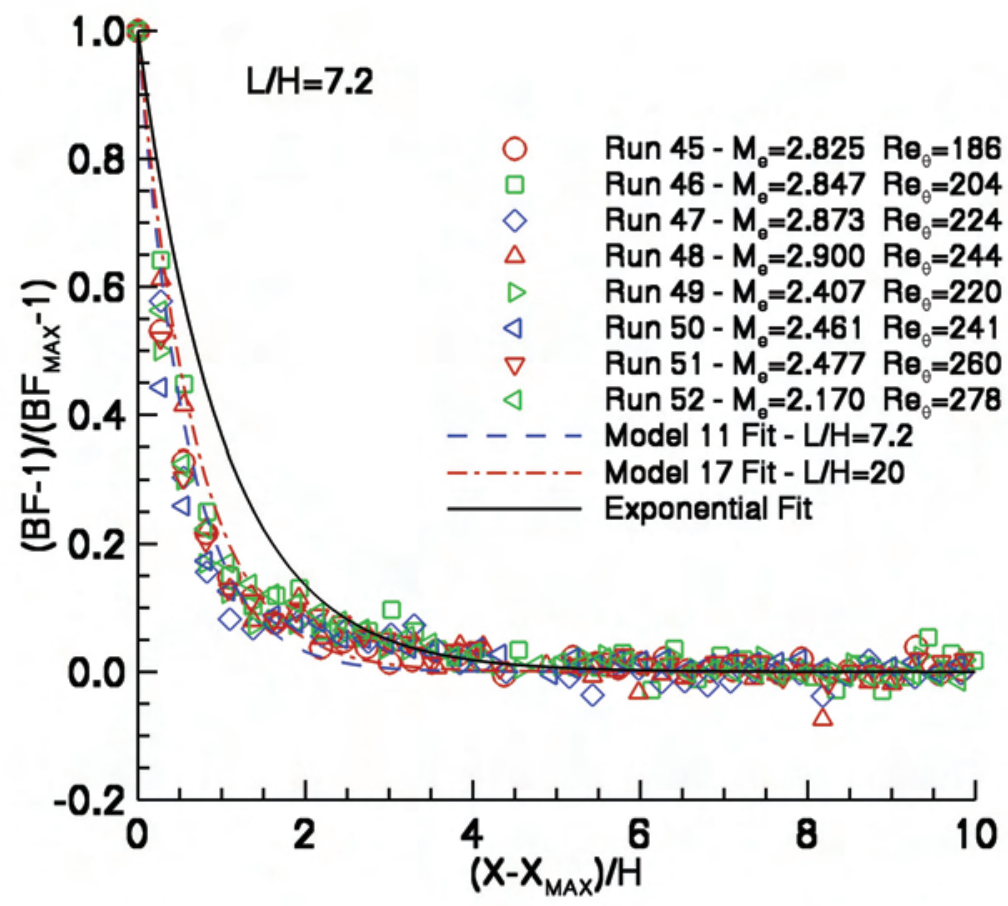

Figure 10. Cavity heating disturbance decay rate for Test 406 Model 11 (L/H=7.2). 


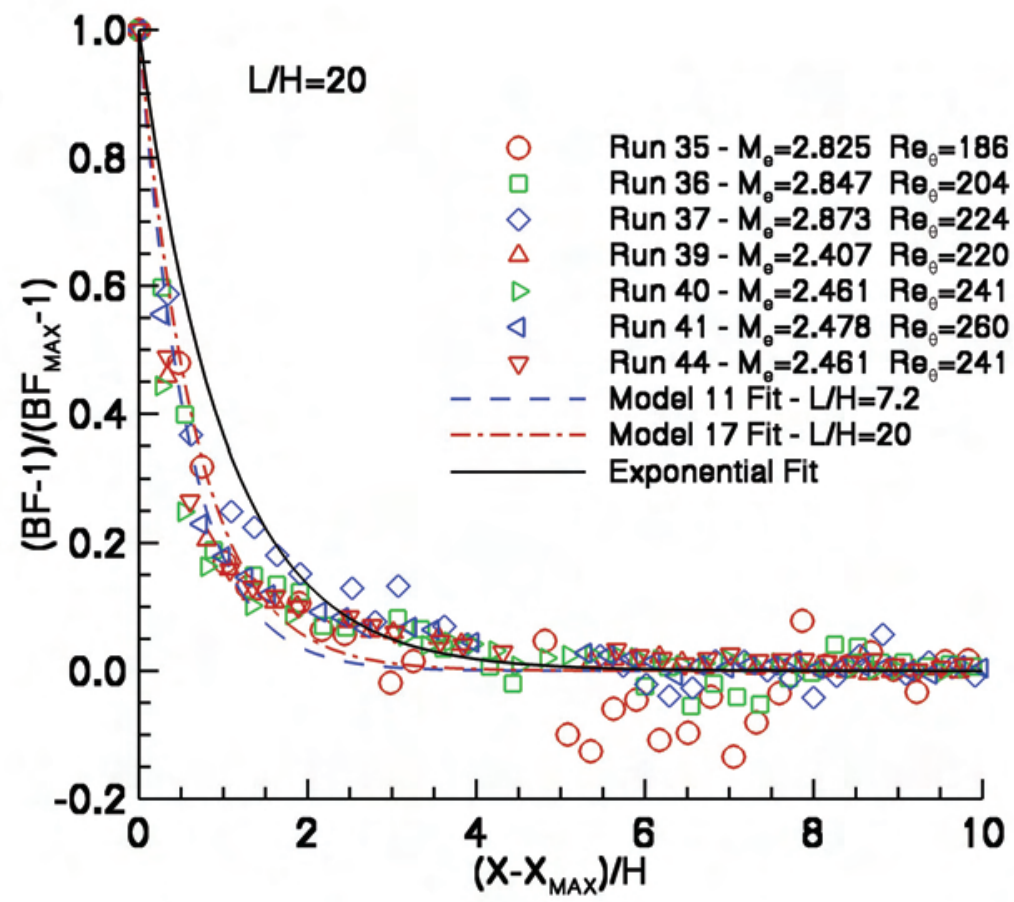

Figure 11. Cavity heating disturbance decay rate for Test 406 Model $17(\mathrm{~L} / \mathrm{H}=20)$.

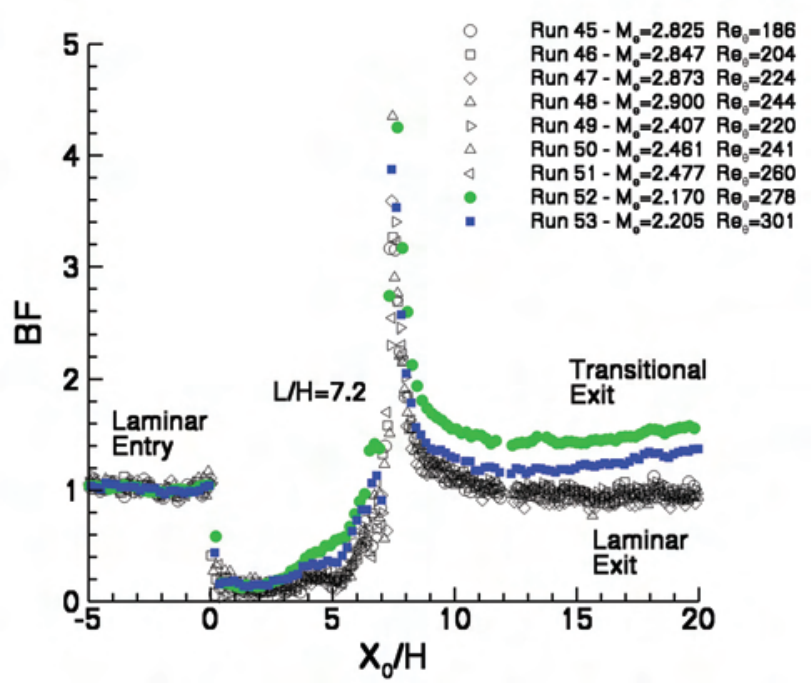

a) $\mathrm{L} / \mathrm{H}=7.2$.

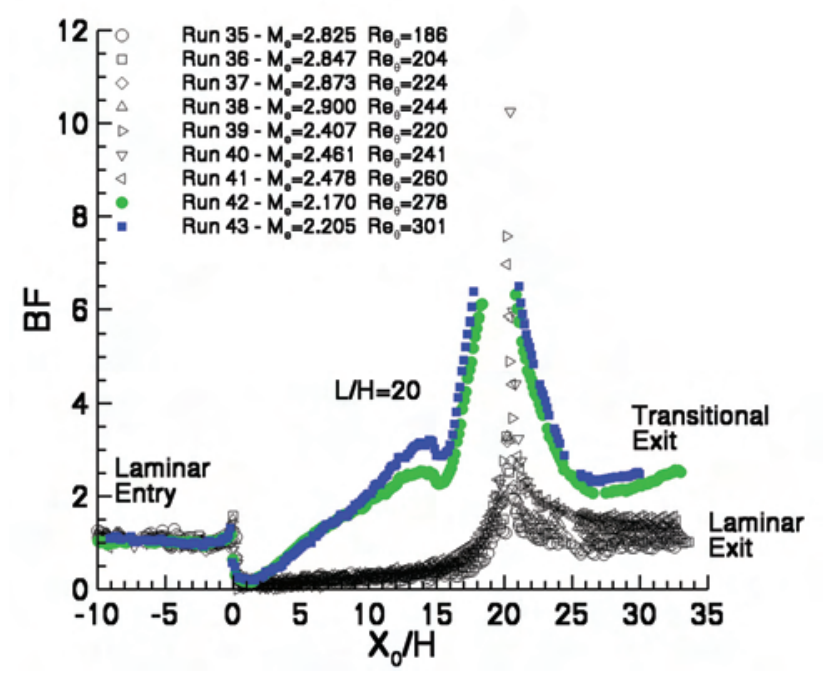

b) $\mathrm{L} / \mathrm{H}=20$.

Figure 12. Representative centerline Bump Factor distributions from Mach 10 Test 406. Turbulent heating levels are $3 \mathrm{X}$ laminar levels. 


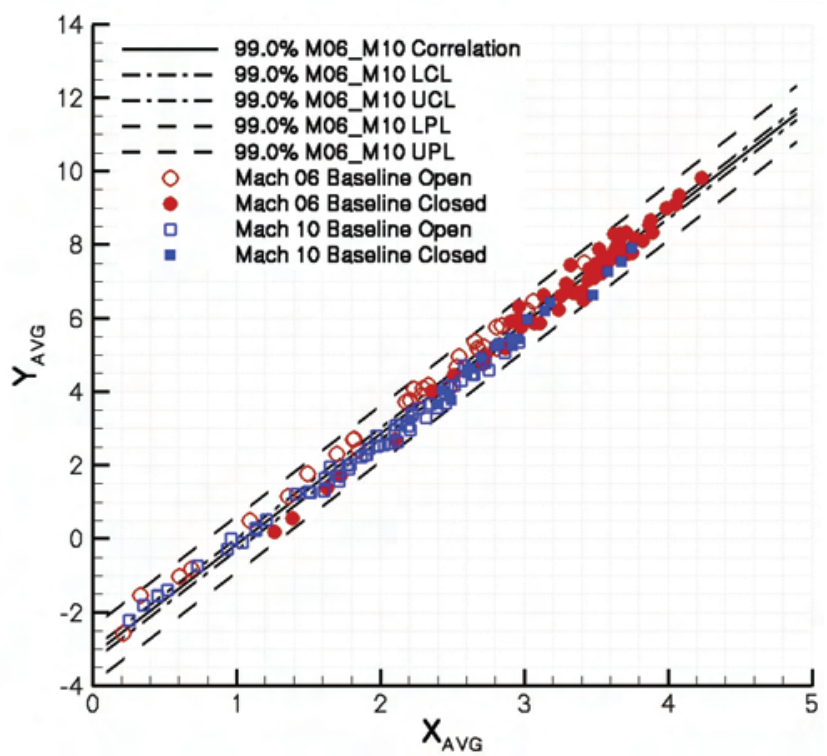

a) Cavity floor correlation.

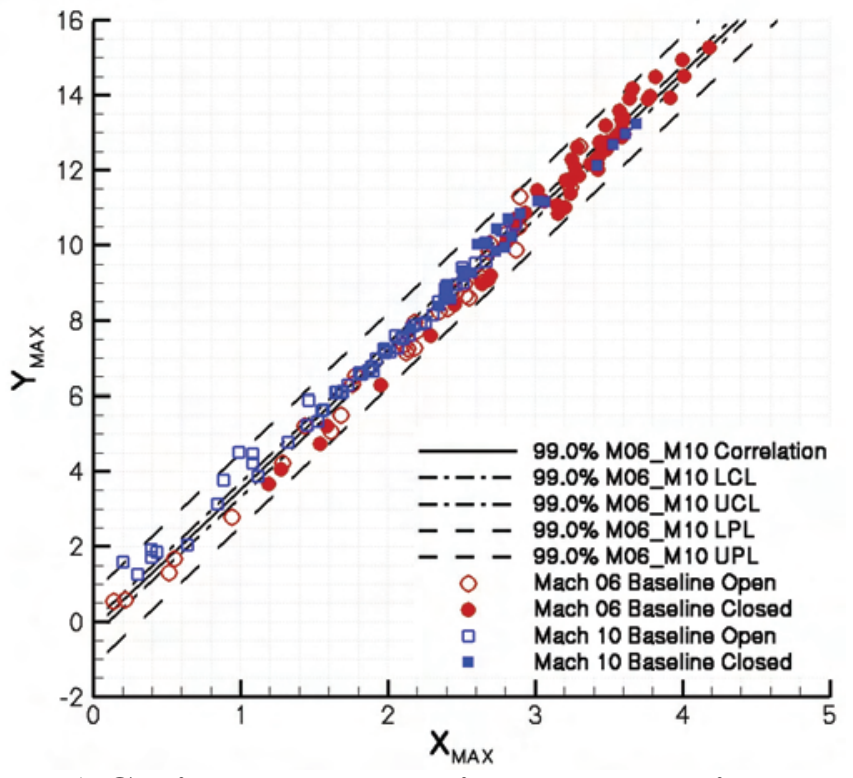

b) Cavity endwall maximum correlation.

Figure 13.- Comparison of baseline Mach 6 and Mach 10 laminar correlation parameters with 99\% combined Mach 6/Mach 10 laminar correlation.

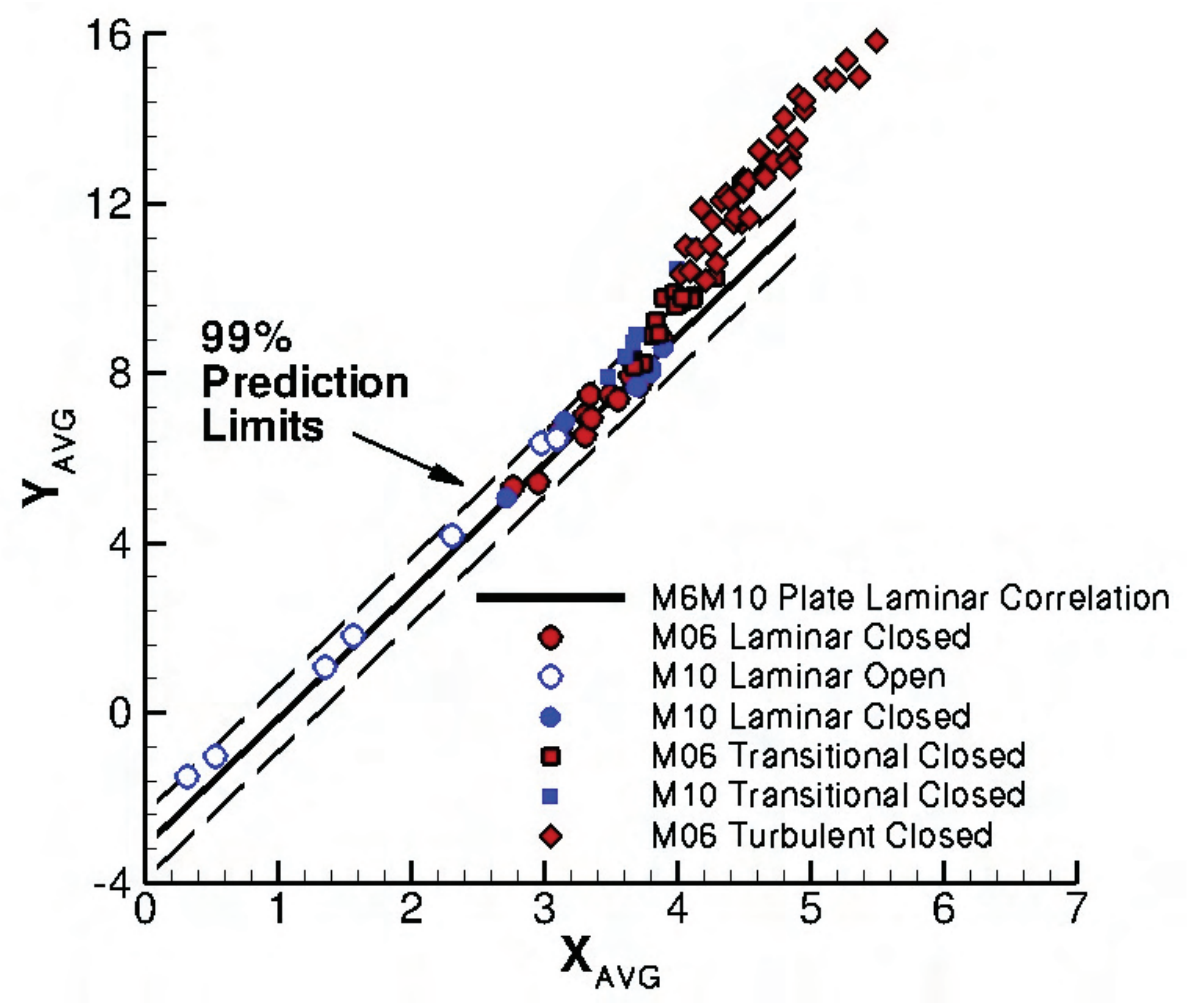

Figure 14. Flat plate cavity $B F_{A V G}$ with boundary layer transition compared to laminar correlation. 


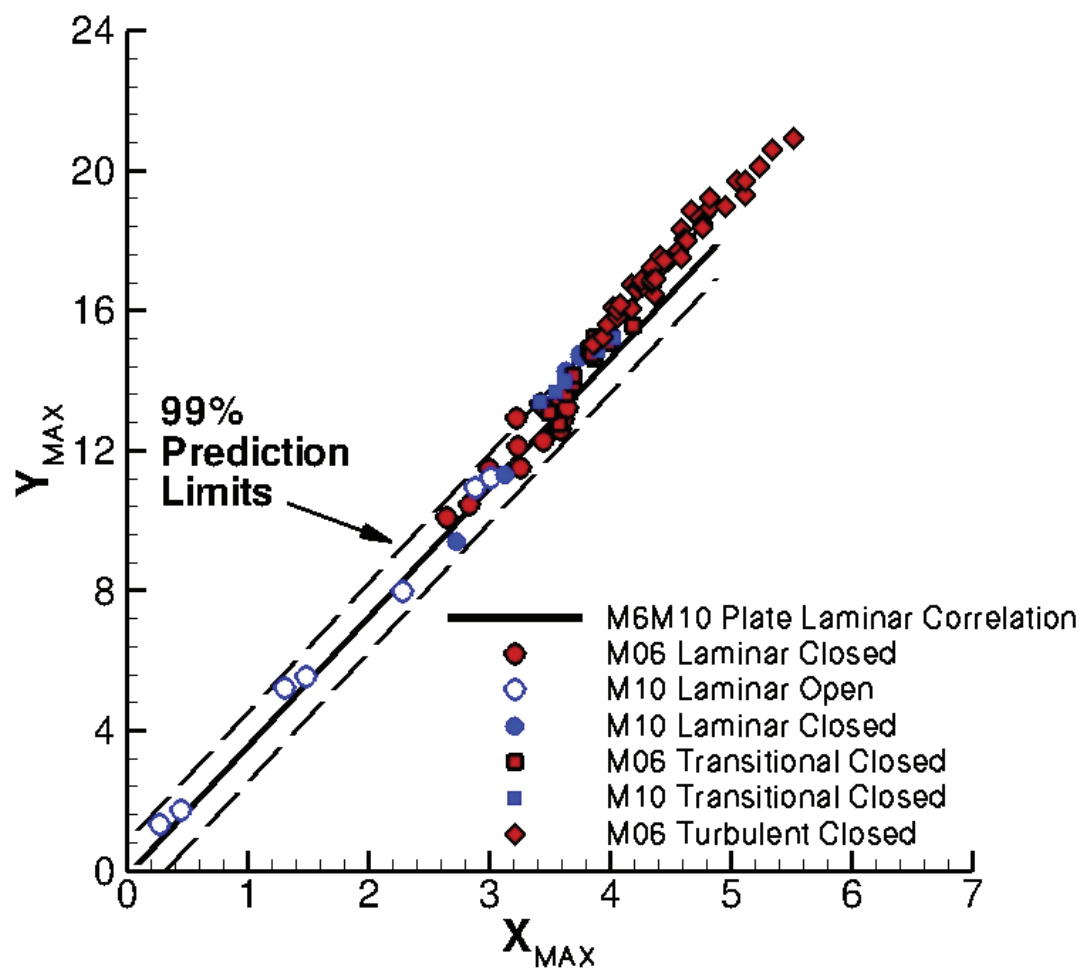

Figure 15. Flat plate cavity $B F_{M A X}$ with boundary layer transition compared to laminar correlation.

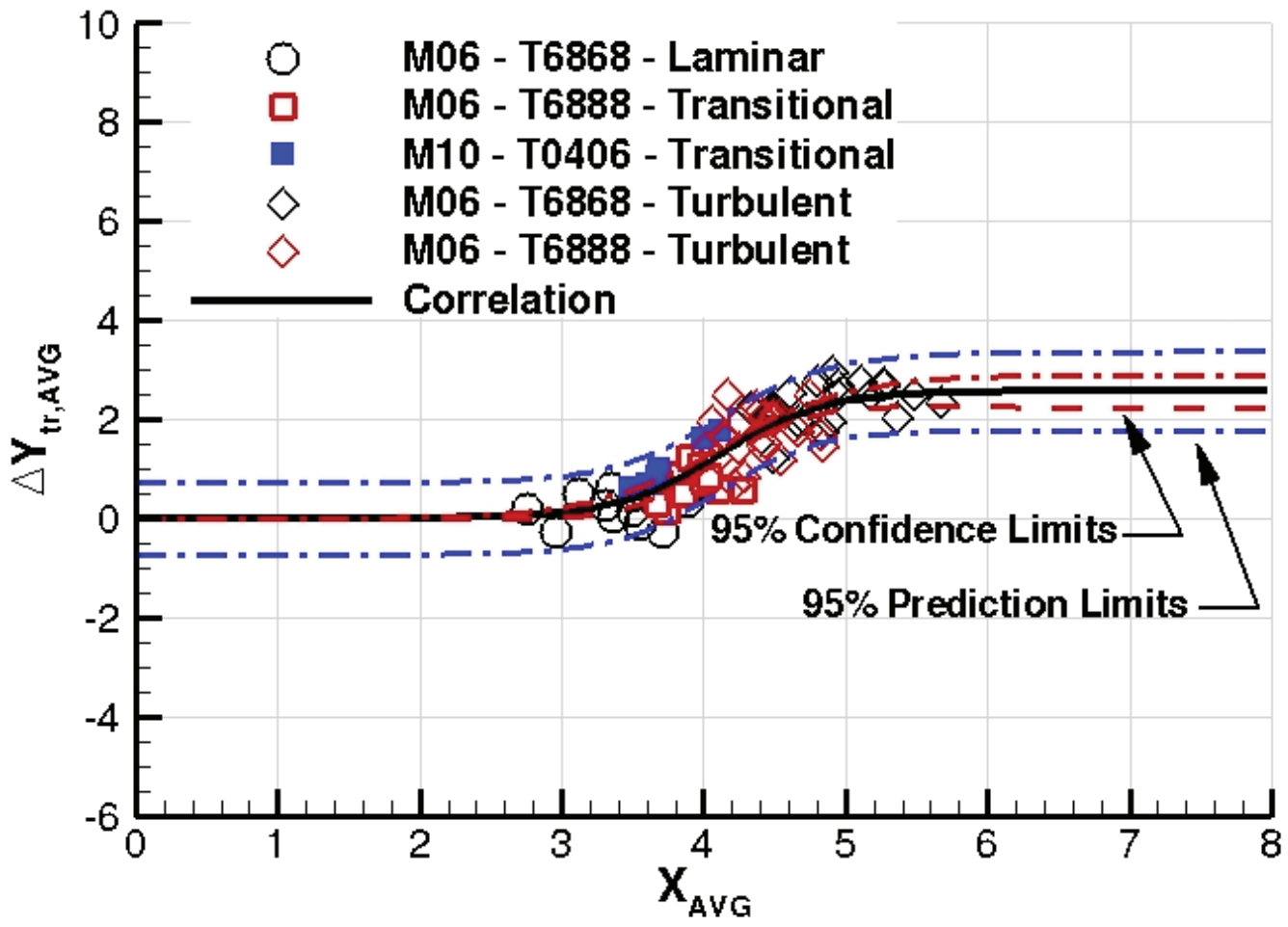

Figure 16. The Transitional $B F_{A V G}$ Augmentation Correlation Curve. 


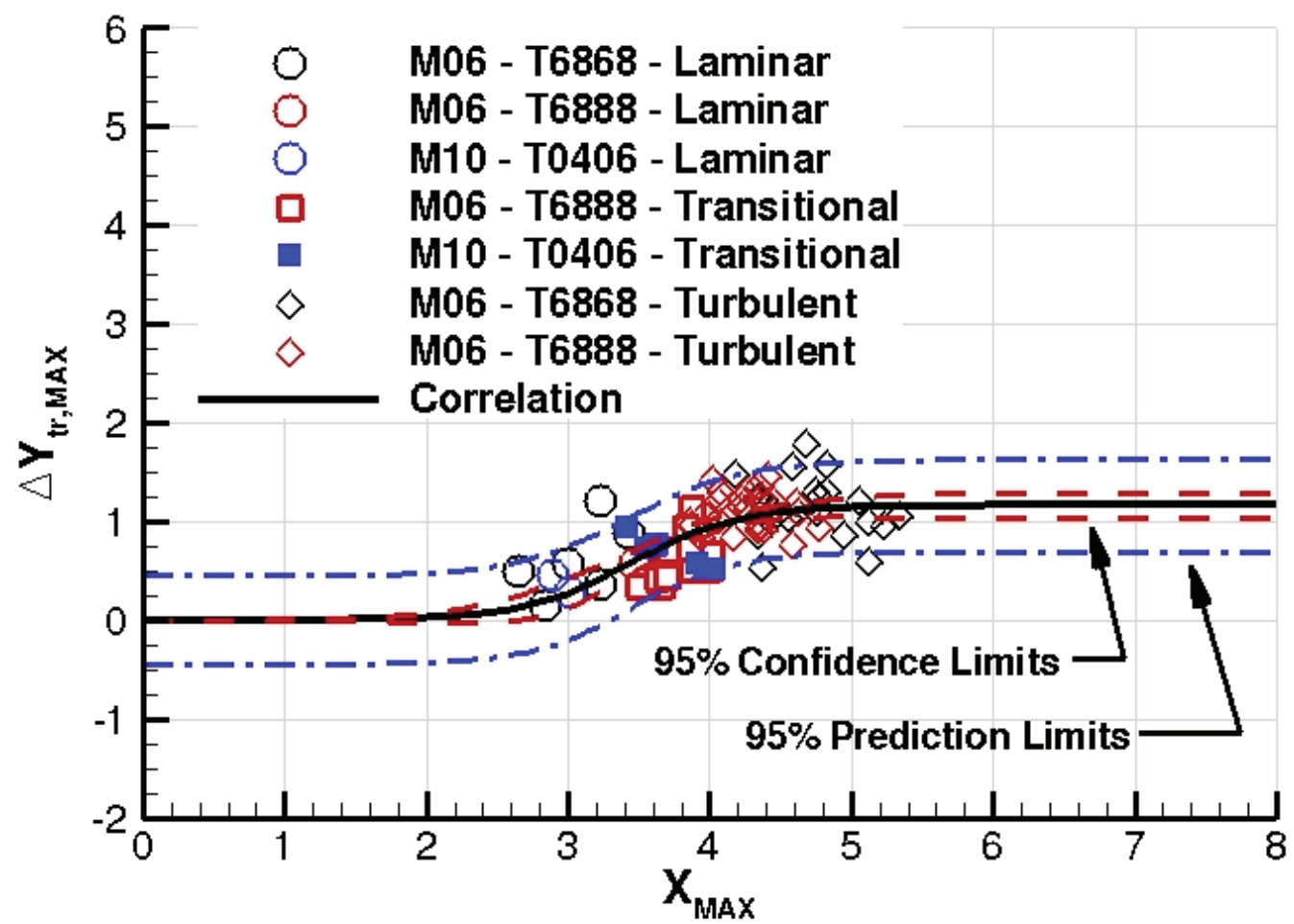

Figure 17. The Transitional $B F_{M A X}$ Augmentation Correlation Curve.

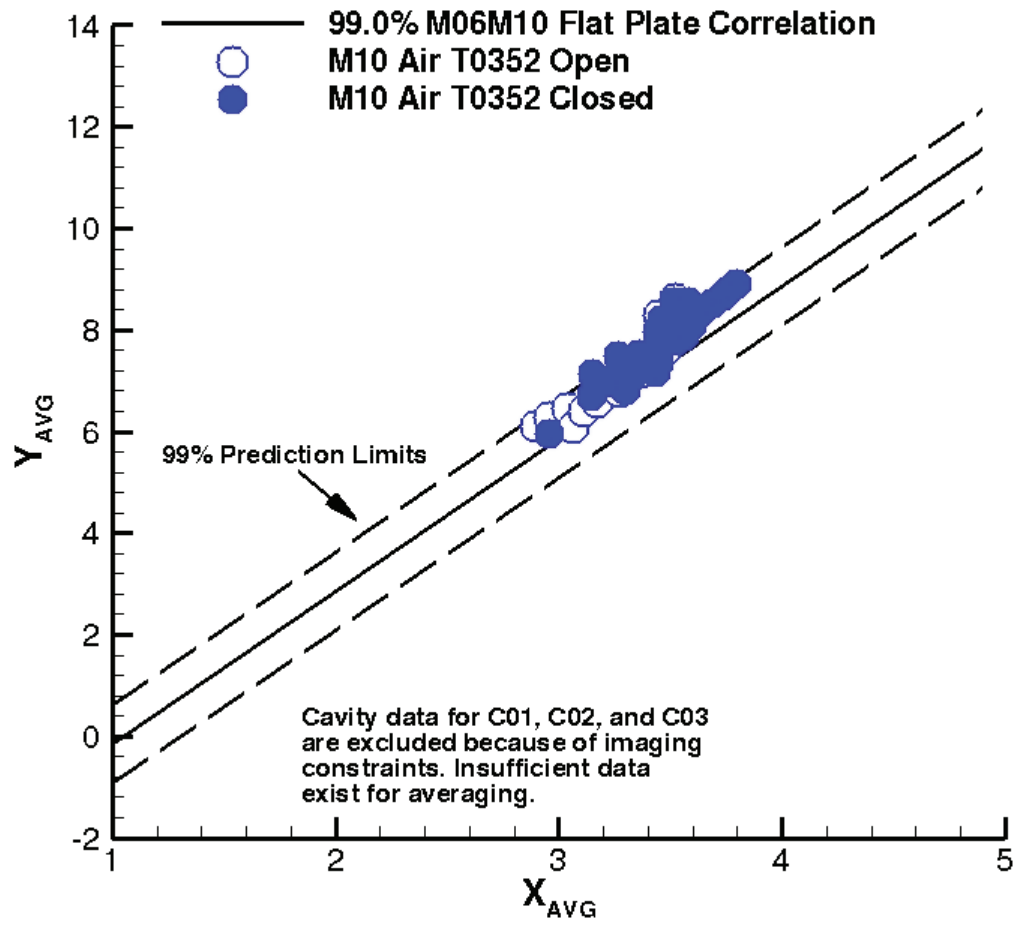

Figure 18. Shuttle Mach 10 Air data compared with Laminar Cavity Heating Correlation. 


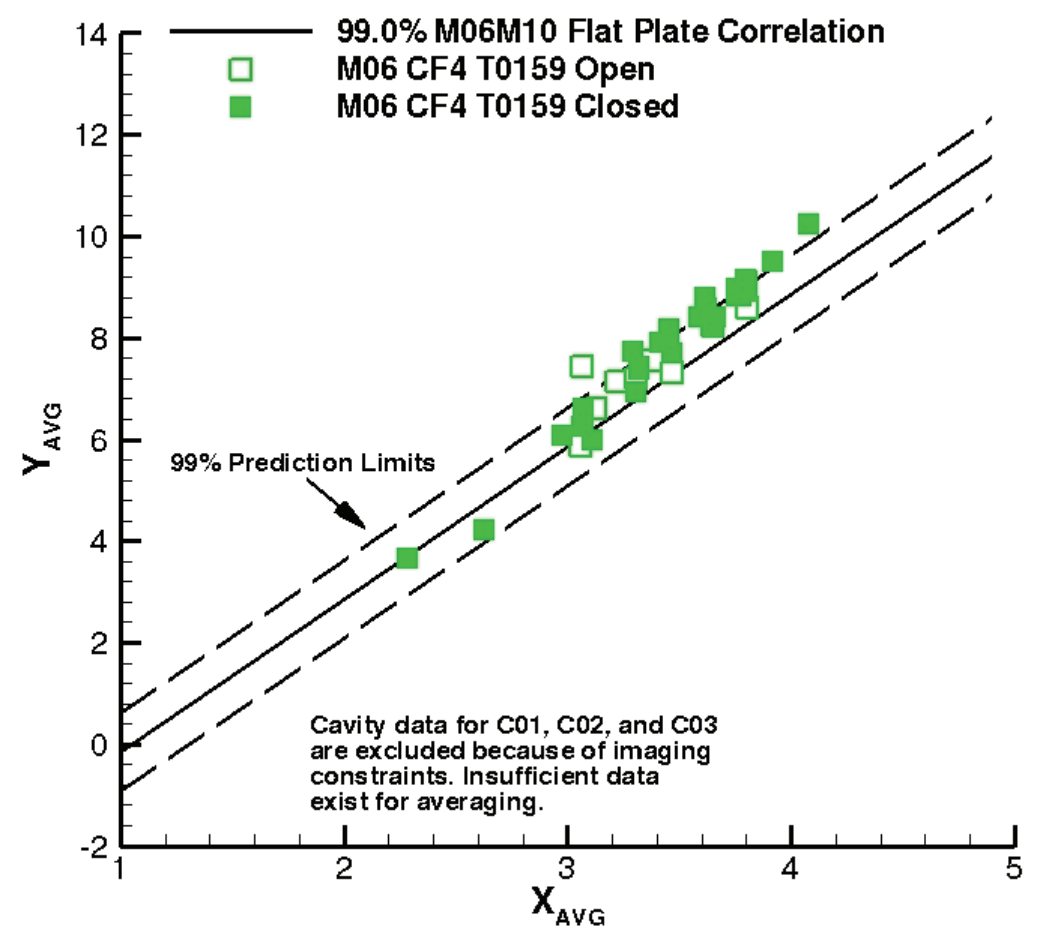

Figure 19. Shuttle Mach 6 CF4 data compared with Laminar Cavity Heating Correlation.

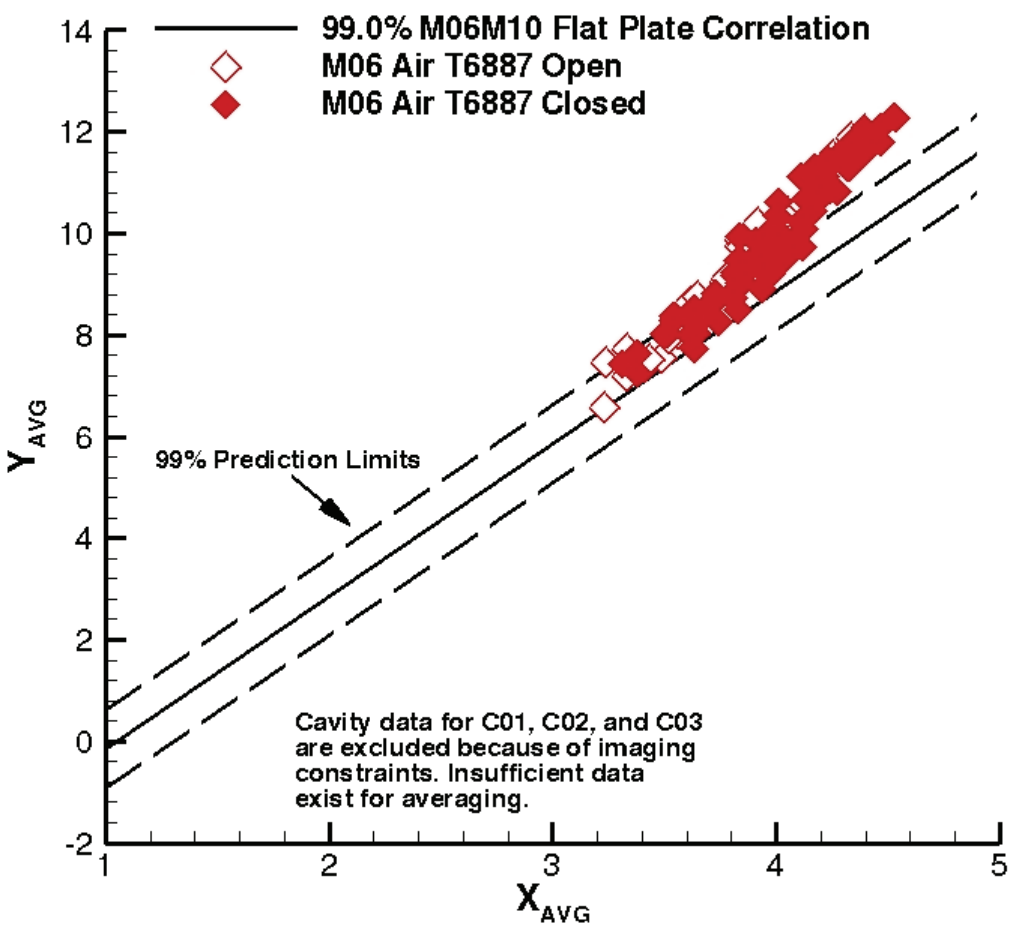

Figure 20. Shuttle Mach 6 Air data compared with Laminar Cavity Heating Correlation. 


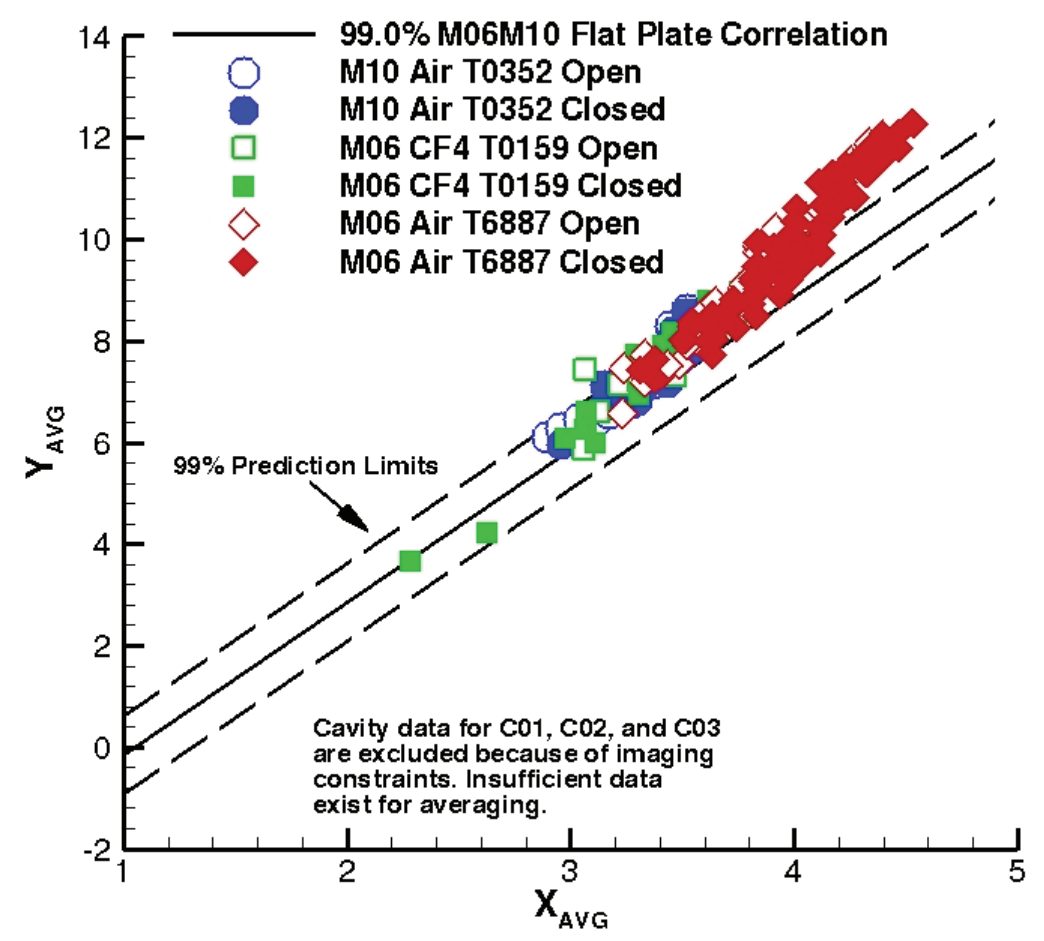

Figure 21. Aggregate comparison of Shuttle cavity data with Laminar Heating Correlation.

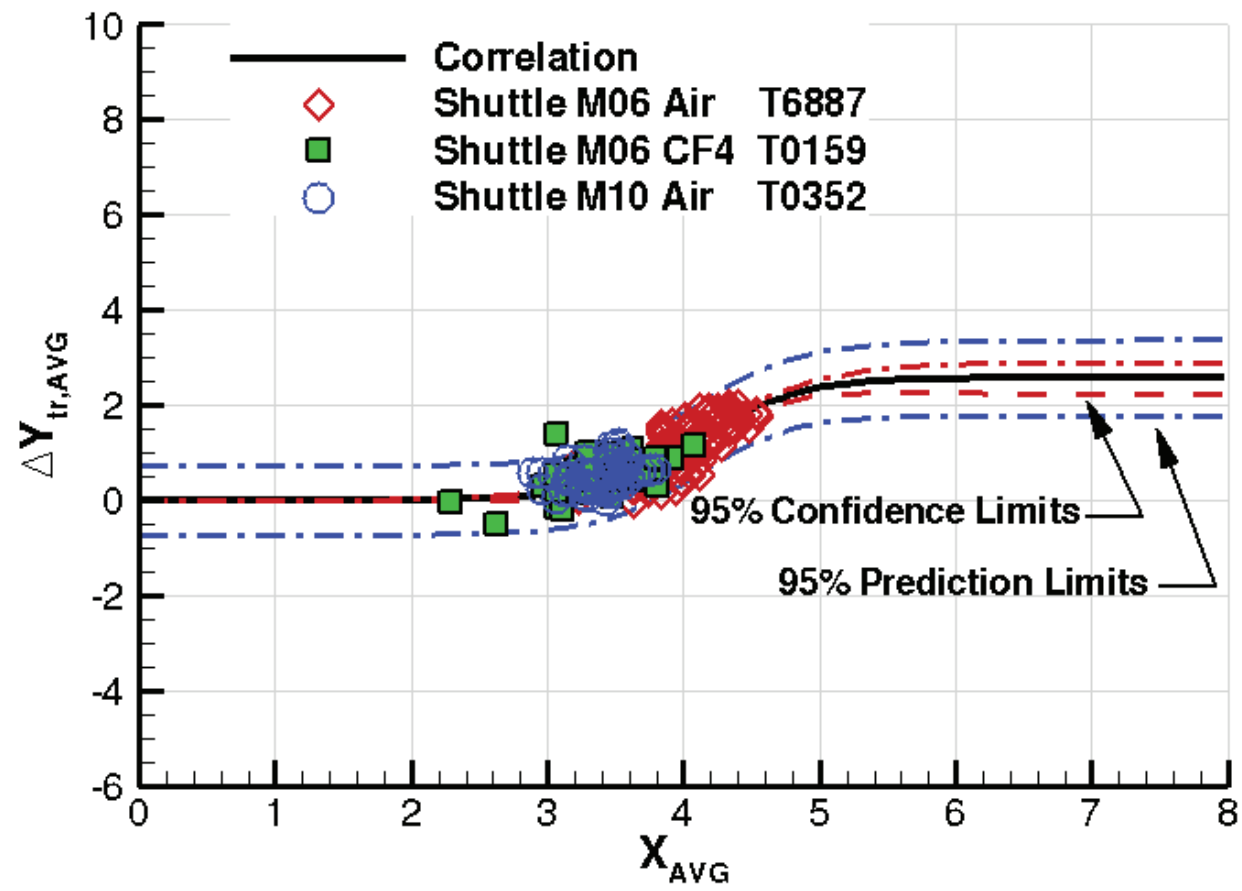

Figure 22. Comparison of Shuttle cavity transition with the flat plate transition correlation. 